\title{
A panoramic view and swot analysis of artificial intelligence for achieving the sustainable development goals by 2030: progress and prospects
}

\author{
Iván Palomares $^{1,2} \cdot$ Eugenio Martínez-Cámara $^{1} \cdot$ Rosana Montes $^{1}$ (D) $\cdot$ Pablo García-Moral $^{3} \cdot$ Manuel Chiachio $^{1}$. \\ Juan Chiachio ${ }^{1}$ - Sergio Alonso ${ }^{1}$. Francisco J. Melero ${ }^{1}$. Daniel Molina ${ }^{1}$ - Bárbara Fernández ${ }^{4}$. \\ Cristina Moral ${ }^{4}$ - Rosario Marchena ${ }^{4}$ - Javier Pérez de Vargas ${ }^{5}$. Francisco Herrera ${ }^{1,5}$
}

Accepted: 4 February 2021 / Published online: 11 June 2021

(C) Springer Science+Business Media, LLC, part of Springer Nature 2021

\begin{abstract}
The 17 Sustainable Development Goals (SDGs) established by the United Nations Agenda 2030 constitute a global blueprint agenda and instrument for peace and prosperity worldwide. Artificial intelligence and other digital technologies that have emerged in the last years, are being currently applied in virtually every area of society, economy and the environment. Hence, it is unsurprising that their current role in the pursuance or hampering of the SDGs has become critical. This study aims at providing a snapshot and comprehensive view of the progress made and prospects in the relationship between artificial intelligence technologies and the SDGs. A comprehensive review of existing literature has been firstly conducted, after which a series SWOT (Strengths, Weaknesses, Opportunities and Threats) analyses have been undertaken to identify the strengths, weaknesses, opportunities and threats inherent to artificial intelligence-driven technologies as facilitators or barriers to each of the SDGs. Based on the results of these analyses, a subsequent broader analysis is provided, from a position vantage, to (i) identify the efforts made in applying AI technologies in SDGs, (ii) pinpoint opportunities for further progress along the current decade, and (iii) distill ongoing challenges and target areas for important advances. The analysis is organized into six categories or perspectives of human needs: life, economic and technological development, social development, equality, resources and natural environment. Finally, a closing discussion is provided about the prospects, key guidelines and lessons learnt that should be adopted for guaranteeing a positive shift of artificial intelligence developments and applications towards fully supporting the SDGs attainment by 2030 .
\end{abstract}

Keywords Sustainable development goals $\cdot$ Artificial intelligence $\cdot$ Emerging digital technologies

\section{Introduction}

Digital technologies are characterized by their innovative nature. These technologies have the capacity to rapidly evolve and adapt to different sectors as their common ground, thereby giving rise to new business models [13]. In particular, Artificial Intelligence (AI) and digital

This article belongs to the Topical Collection: 30th Anniversary Special Issue

Rosana Montes

rosana@ugr.es

Extended author information available on the last page of the article. technologies surrounding it, such as big data, blockchain, cloud, virtual and augmented reality, etc., are revolutionizing our society, propelling its transformation in the current age of the so-called Fourth Industrial Revolution [4-6]. In essence, these technologies are expected to consolidate as a societal and economic lever for transformation at global scale.

AI has currently reached a sufficient level of maturity both as an umbrella scientific discipline and as a technology, having spread from laboratories to the entire society. Industry and government administrations make an increasingly extended use of intelligent and digital technologies in their daily projects and endeavors [7-9]. The economic impact of AI has grown considerably in the last years, and recent studies predict a 15 -billion economic impact by year 2030 [10]. For these reasons, AI could -and must- further 
the attainment of the 17 Sustainable Development Goals (SDGs) established in the United Nations' Agenda 2030, becoming a facilitator to achieve the 169 targets underlying such goals.

In recent years, several studies have arisen to examine the challenges, benefits and potential impacts of the AI [11-14] and related technologies (e.g. blockchain [15, 16]) as catalysts for the whole compendium of SDGs. Aspects including the impact of AI in sustainability case studies [11], regulatory approaches to minimize the negative impact of AI on SDGs [12], systematically assessing the current effects of AI in each of the SDG targets [13], or awareness-raising on pushing technological innovations ahead [14], have been discussed. Meanwhile, based on an in-depth literature review and guided by the insights provided in the aforesaid studies, our focus consists in uncovering both the road travelled so far and the pending road ahead in leveraging AI technologies for achieving the SDGs by 2030. Specifically, our double aim is: (i) to identify (predicated on SWOT analyses) the most remarkable opportunities and challenges to advance towards the fulfillment of the SDGs in all their dimensions along the next decade, with the aid and recent progress made across the AI landscape; and (ii) to propose a "decade roadmap" of future actions and guidelines to consider for maximizing the attainment of this ambitious, yet much needed global agenda.

Accordingly, this paper provides a panoramic view and a comprehensive reflection about the double-sided role that the AI and digital technologies closely tied to it have played so far, and could potentially play, in achieving the SDGs by 2030 . The strengths and prospects to embrace in these technologies are highlighted on the one hand, along with the difficulties and potential threats they can also pose on the other hand. Following a substantial revision of related literature lying at the intersection between AI and the SDGs, the study provides a fourfold contribution:

- A synthesis summary and classification of surveyed literature where AI applications in the SDGs have been investigated, distinguishing between scientific publications and dissemination works, and identifying the target SDG each study focuses on. We provide all the references studied in a spreadsheet format as supplementary material. ${ }^{1}$

- As a result of the reviewed literature, a comprehensive SWOT analysis is undertaken for each of the SDGs by identifying the strengths, weaknesses, opportunities and threats that AI can bring in each goal.

\footnotetext{
${ }^{1}$ https://github.com/ari-dasci/OD-AI-SDG
}

- Based on the SWOT analyses, a snapshot analysis regarding six dimensions and perspectives of human needs is provided on the main prospects and recommendations for progress in attaining the SDGs along the 2020-30 decade.

- Lastly, a broader discussion is made with a focus on upcoming developments. Specifically, a roadmap of five key elements or priorities to consider along the next decade is proposed, providing insights and underlining lessons learnt to maximize the positive impact that AI could play to achieve the SDGs by 2030.

The paper is organized as follows. Section 2 introduces the 17 SDGs and categorizes them into three dimensions economic, social and environmental- and six perspectives of human needs, inspired by [14]. Section 3 provides a brief tour through AI, its disciplines and related digital technologies, followed by a brief description of the literature survey conducted and an overview of various general studies focused on using AI to address the SDGs as a whole. In Section 4, a SWOT analysis on the use of AI and digital technologies for achieving the SDGs is taken as the input for introducing a snapshot analysis of prospects and recommended courses of action for this end, identifying challenges and areas for further action in every dimension and perspective of sustainability. Section 5 discusses a series of key elements for consolidating an use of AI aligned with the SDGs over the course of the coming years, and Section 6 concludes the paper.

\section{Sustainable development goals: six perspectives of human needs}

This section introduces the SDGs outlining their overall mission, and provides a categorization of the goals in accordance with six dimensions or perspectives of human needs.

The 17 Sustainable Development Goals (SDGs) were approved by member countries of the United Nations as the building blocks of the 2030 Agenda for sustainable development. ${ }^{2}$ They constitute a global blueprint agenda and instrument for peace and prosperity for people and the planet, considering aspects like eradicating poverty and hunger, protecting the environment and its resources, reducing vulnerabilities and combating inequalities, amongst others. The SDGs are envisaged as a universal instrument to support sustainable development in all countries regardless

\footnotetext{
${ }^{2} 2030$ Agenda for Sustainable Development: https://sustainabledevelopment. un.org/post2015/transformingourworld
} 
of their actual development status. The nature and fundamental rationale behind each of the 17 goals is summarized in Table 1.
The SDGs have a clearly defined focus on different aspects of economy, society and the environment. Accordingly, several categorizations that arose across disciplines

Table 1 The 17 Sustainable Development Goals (SDGs) Source [17]

Sustainable Development Goals

Goal 1: No poverty

- End poverty in all its forms everywhere.

Goal 2: Zero hunger

- End hunger, achieve food security and improved nutrition and promote sustainable agriculture.

[6pt] Goal 3: Good health and wellbeing

- Ensure healthy lives and promote wellbeing for all at all ages.

Goal 4: Quality education

- Ensure inclusive and equitable quality education and promote lifelong learning opportunities for all.

Goal 5: Gender equality

- Achieve gender equality and empower all women and girls.

Goal 6: Clean water and sanitation

- Ensure availability and sustainable management of water and sanitation for all.

Goal 7: Affordable and clean energy

- Ensure access to affordable, reliable, sustainable and modern energy for all.

Goal 8: Decent work and economic growth

- Promote sustained, inclusive and sustainable economic growth, full and productive employment and decent work for all.

Goal 9: Industry, innovation and infrastructure

- Build resilient infrastructure, promote inclusive and sustainable industrialization and foster innovation.

Goal 10: Reduced inequalities

- Reduce inequality within and among countries.

Goal 11: Sustainable cities and communities

- Make cities and human settlements inclusive, safe, resilient and sustainable.

Goal 12: Responsible consumption and production

- Ensure sustainable consumption and production patterns.

Goal 13: Climate action

- Take urgent action to combat climate change and its impacts.

Goal 14: Life below water

- Conserve and sustainably use the oceans, seas and marine resources for sustainable development.

Goal 15: Life on land

- Protect, restore and promote sustainable use of terrestrial ecosystems, sustainably manage forests, combat desertification, and halt and reverse land degradation and halt biodiversity loss.

Goal 16: Peace, justice and strong institutions

- Promote peaceful and inclusive societies for sustainable development, provide access to justice for all and build effective, accountable and inclusive institutions at all levels.

Goal 17: Partnerships for the goals

- Strengthen the means of implementation and revitalize the global partnership for sustainable development. 
have been established in recent literature to classify them into several dimensions, such as $[13,14]$. In this study we build upon the two-level categorization proposed by $\mathrm{Wu}$ et al. in [14]. The first level distinguishes between three major dimensions or areas of human needs to be satisfied for achieving sustainability: economic, social and environmental; each of which is decomposed into two perspectives, as shown in Fig. 1 and described below:

- Economic dimension: It focuses on sustainable development at an economic level and considering the prosperity and welfare of the individuals. This dimension is subdivided into two perspectives: (i) life, related to poverty reduction, food sustenance and health; (ii) economic and technological development, concerned with economic growth, sustainable industrialization and innovation.

- Social dimension: It concentrates on sustainable development in terms of equality, welfare and prosperity of communities. This dimension is subdivided into two perspectives: (i) social development, related to sustainable communities, peace, justice and global partnerships; (ii) equality in access to education and employment, gender, and other factors.

- Environmental dimension: It pertains the preservation of the environment and the management of its key resources to safeguard sustainability. This dimension is subdivided into two perspectives: (i) resources, including water, clean energy, responsible production and consumption; (ii) natural environment, centered on climate, land and underwater ecosystems.
This classification is adopted in the analyses presented in Section 4 of this paper. Albeit this grouping approach for the SDGs is largely inspired by the work in [14], it is worth noting that the scope of the SDG 14, life below water, originally classified under the resources perspective in the aforesaid work, has been relocated to the natural environment perspective of the environmental dimension in our study.

\section{Artificial intelligence and emerging technologies}

The development and implementation of new technologies usually raises certain fear and aversion amongst people against them. This sense of antagonism is typically motivated by collective lack of knowledge or familiarity towards the features and potential benefits of these technologies. AI in particular currently originates some degree of hostility in certain communities, owing to the feeling that its extensive use may trigger unknown changes in human daily lives. Nonetheless, the use of AI is enabling the automation, traceability and optimization of several human activities, many of which would facilitate the attaining of the SDG.

Accordingly, in this section we aim at presenting an overview of the AI landscape and showing the potential benefits of AI to help achieving the SDGs. We firstly provide a definition of AI and its core disciplines in Section 3.1, followed by a snapshot of its related digital technologies in Section 3.2. A summary of a literature review conducted on the application of AI in tasks concerning the SGDs, along
Fig. 1 Classification of the SDGs into three dimensions and six perspectives of human needs
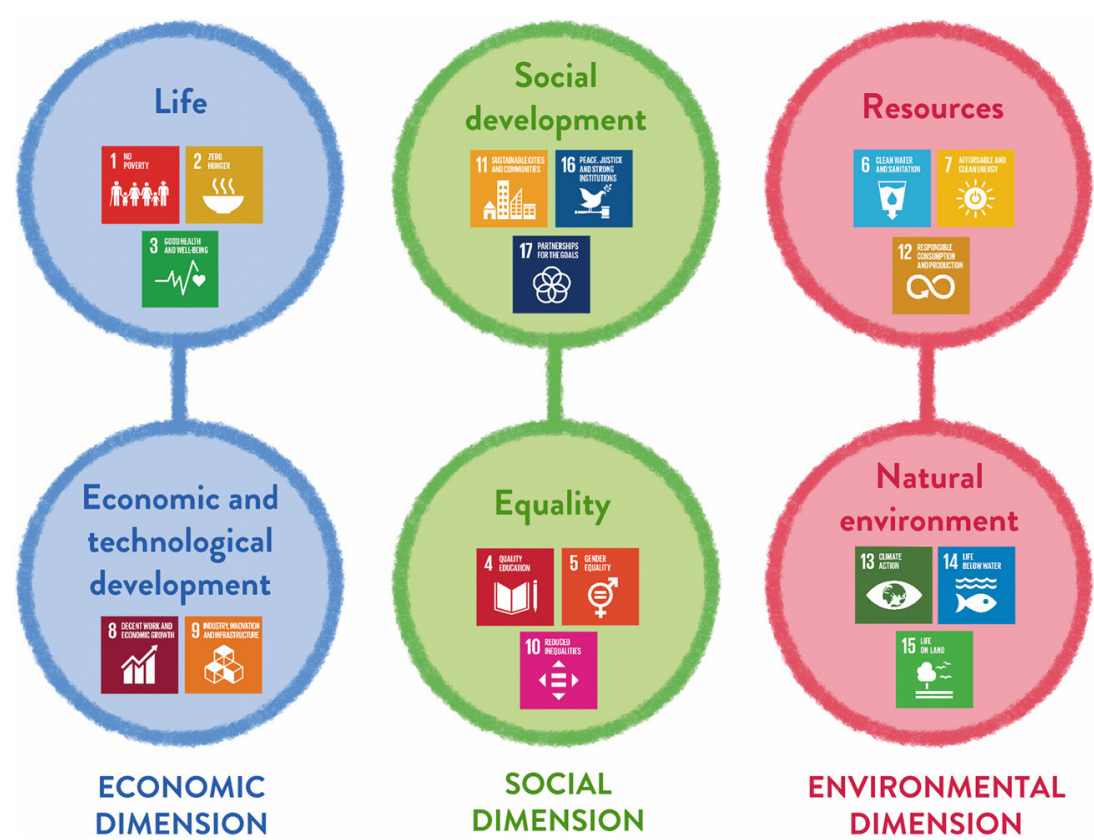
with a general view of how IA may contribute to reach the SGDs, are then provided in Section 3.3.

\subsection{A bird's-eye view on artificial intelligence}

AI was coined and defined by Jonh McCarthy in [18] as the science and engineering of making machines that behave in ways that would be called intelligent if a human were behaving so. This connection among human and artificial intelligence is also expounded by Tegmark in [19], who asserts that $\mathrm{AI}$ is a non-biological intelligence. Thus, it is firstly necessary to know what is intelligence, which can be defined as the ability to accomplish complex goals [19], more concretely based on the available environment information. Hence, AI aims at accomplishing complex goals using the input data as source of information describing the environment. Therefore, an AI system can be formally defined as "software (and possibly also hardware) systems designed by humans that, given a complex goal, act in the physical or digital dimension by perceiving their environment through data acquisition, interpreting the collected structured or unstructured data, reasoning on the knowledge, or processing the information derived from data to ultimately decide the best course(s) of action to achieve a given goal. AI systems can either use symbolic rules or learn a numerical model, and they can also adapt their behaviour by analysing how the environment is affected by their previous actions" [20].

According to the previous definition, illustrated by Fig. 2, the main elements of an $\mathrm{AI}$ system are:

- Computational system. A software or hardware system with the capacity of processing data through algorithms.

- Data. The representation of the environment, and an indispensable element for AI algorithms that learn the optimal way to reach their goals. It is noteworthy that in accordance with the AI definition expounded in [20], the term "percepts" is used in Fig. 2 when referring to input data perceived from the environment.

- Goal. It represents the task to accomplish by the AI system, guided by the input data.

The end goal implied by the above AI definition is making intelligent systems whose behavior resembles human intelligence behaviour, in line with the original motivations behind the Turing test introduced in the 1950 [21]. This kind of intelligent behaviour requires that a system meets a
Fig. 2 An AI system collects data from its environment and processes it to learn the way to achieve the goal for it was designed

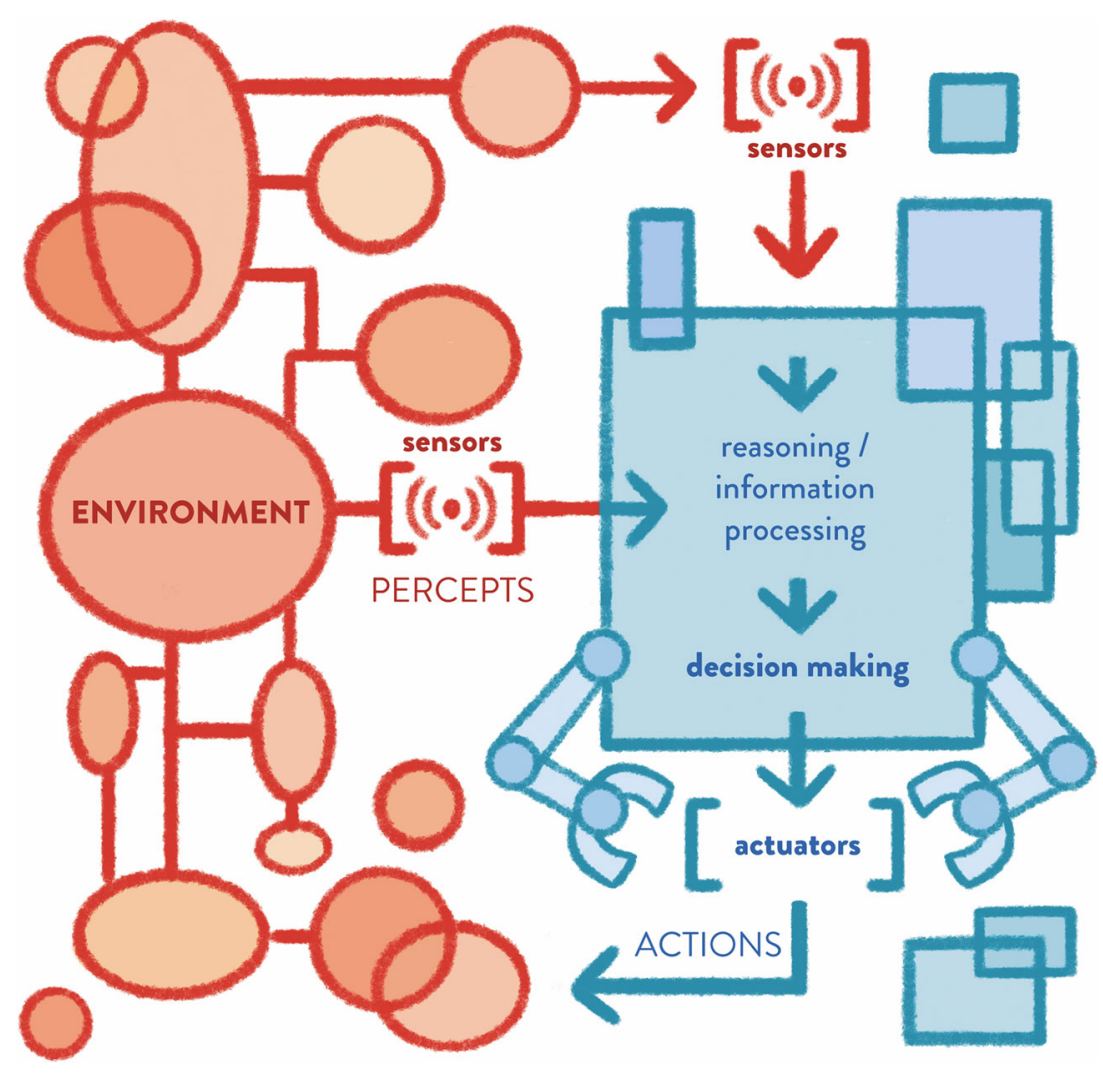


number of skills, most of which match some of the currently established areas within AI [22], namely:

- Knowledge representation. It allows systems to represent the input data in a specific format that can be stored and processed.

- Natural language processing. It enables systems to understand and generate human language.

- Computer vision. It allows to process visual input data, and by extension to perceive physical objects.

- Machine learning. It provides the capacity to extrapolate patterns, to adapt to new scenarios, and to learn from examples.

- Automated reasoning. It enables the use of information and knowledge stored to answer questions or to perform specific actions according to the input data and such information/knowledge stored.

The skills listed above demand in turn the ability of learning some kind of behaviour, in other words, learning how to understand natural language, learning how to perceive objects, learning how to extrapolate patterns, etc. There are two major disciplines in AI that focus on endowing AI systems with the capacity for reasoning and learning:

Reasoning and decision making. This group of AI methods allow to perform reasoning processes predicated on input data. The first step in these processes pertains representing the underlying knowledge to the data (knowledge representation), after which the system would be able to reason over that knowledge (knowledge reasoning). Reasoning generally boils down to making inferences through symbolic rules, planning and scheduling activities, searching through a large solution space, optimizing the solution to a problem, or the combination of any of these tasks.

Learning. There are problems that cannot be represented as symbolic rules, and they have to be learnt by processing of known (data) examples or observations in order to infer or predict new outcomes associated to unknown observations. For instance, it is not possible to represent with symbolic rules all varieties of human speech in speech processing problems, hence we need to resolve these problems by processing a set of examples -e.g. speech recordings- that allows to generalize and process new ones correctly.

Machine learning [23] encompasses an ample family of techniques that learn a mathematical model by processing data examples for resolving an specific task. Although there are a broad spectrum of machine learning approaches, three main classes of techniques can be distinguished:

- Supervised learning. The system learns a model based on annotated data or training data. Since data guide the learning process of the algorithm, they must be representative of the task, otherwise the algorithm would not learn adequately how to deal with the task at hand. There are a large number of supervised machine learning algorithms, among which deep learning methods have stood out in recent years, setting the current state of the art in AI trends such as image and video classification and natural language processing.

- Unsupervised learning. These systems seek patterns by finding similarities on non-annotated data. Examples of unsupervised learning algorithms are: clustering, association rules methods or subgroup discovery methods.

- Reinforcement learning. These techniques are based on rewarding (positive reinforcement) or punishing (negative reinforcement) the algorithm when it makes a good or bad decision during the learning process. The iterative process of rewarding and punishing allows the algorithm to learn an specific task and to self-adapt to unknown situations.

Besides the above disciplines, it is also imperative to highlight robotics as part of the AI landscape, typically referred to as "the AI in the physical world" [20]. A robot can be described as a machine with the capacity of acting and moving in the physical world, and the necessity of dealing with uncertainty and complexity inherent to it. Therefore, a robot has to perceive, namely acquiring input data to reason, to act according to the input data, and to collaborate with other robots. Self-driving cars [24] are an example of robots, which process input data (traffic signals or other cars on the road) for undertaking the most optimal actions in order to reach a goal, e.g. completing a journey. Figure 3 summarizes the areas of AI in conjunction with robotics as their interface with the physical world.

The integration of AI in several spheres of our daily lives raises concerns about the motivation behind decisions made by AI algorithms, as well as the consequences and accountability of those decisions and, in essence, the ethical use and implications of AI. These concerns have stimulated the emergence of recent research trends focused on developing responsible and explainable AI [25] and investigating how to address Fairness, Accountability, Transparency and Ethics (FATE) in AI systems. These efforts toward developing AI systems that are fully trusted by people are positioned under the umbrella concept of trustworthy AI [26], which states that trustworthy AI systems must be:

1. Lawful, respecting all applicable laws and regulations.

2. Ethical, respecting ethical principles as: human dignity, individual freedom, democracy, justice, equality, nondiscrimination, solidarity and citizen rights. 


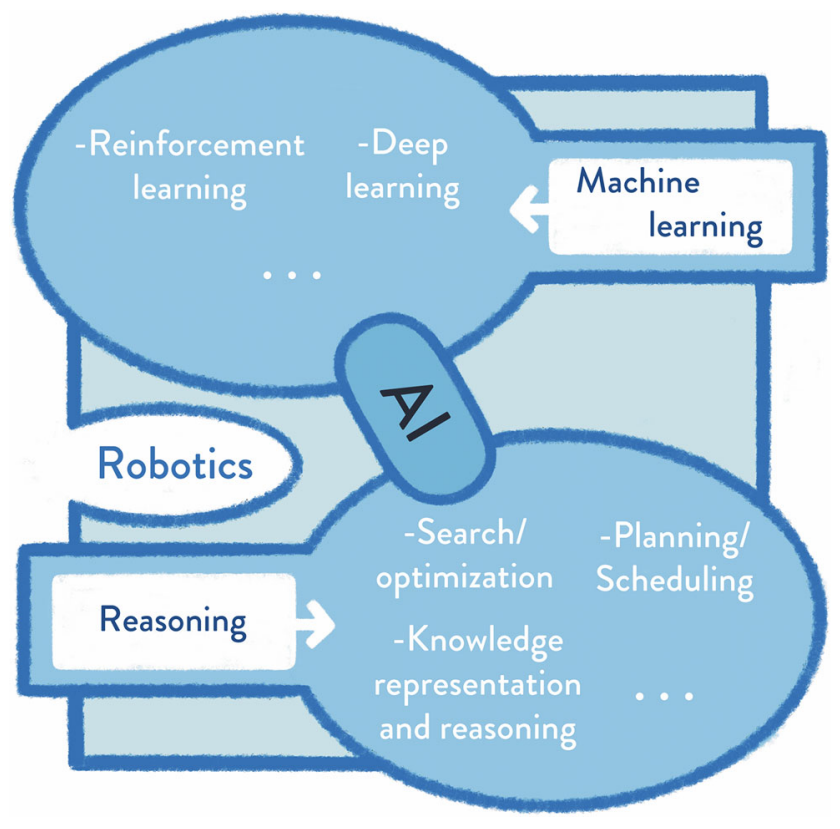

Fig. 3 The AI areas and family methods

3. Robust, whereby AI system must work correctly and ensure that they will not provoke unintentional damage.

The development of a trustworthy $\mathrm{AI}$ is an stimulating challenge and crucial for enabling AI systems that boost the attainment of the SGDs.

\subsection{Integrating artificial intelligence and digital technologies}

Although AI systems are able to learn to accomplish tasks guided by input data, they often necessitate the support of other digital technologies for acquiring, storing, computing and transmitting data. Accordingly, below we briefly outline various digital technologies that symbiotically cooperate with AI in many of the real-world application scenarios linked with attaining the SDGs:

- Internet of Things (IoT). It refers to all interconnected devices able the acquire data and transmit them via Internet [27]. These devices may also conduct some minor data processing operations or tasks.

- $3 D$ technologies. It refers to the technologies with the ability of precisely representing a physical object as a set of data points, for their computational treatment [28, 29]. Computer vision, augmented reality and virtual reality are examples of 3D technologies.

- Blockchain. This technology aims at ensuring the immutability of data, as well as tracing the aggregation of new data blocks. Blockchain keeps a timestamp of those aggregation operations, and it defined over a distributed setting [2].
- $5 G$ communication infrastructure. It refers to the fifth generation of mobile communication technologies, and it stands out for its remarkable capacity to connect millions of devices at a high communication speed, its low latency, low energy consumption and high reliability [30].

- Big data. It encompasses the set of technologies for processing a high volume and variety of data that are generated and updated at high velocity $[31,32]$.

- Digital twin. These technologies are concerned with the representation of a real object with a digital model. This representation requires a real time communication among the physical object and the digital twin in order to ensure a trustworthy digital representation [33].

- Smart Territories. They are the set of technologies used for urban and rural data management, beyond the scope of smart cities [34, 35].

- Emerging technologies. They are a set of technologies -e.g. quantum computing and driver-less cars- that have still not reached their maturity but they raise high expectations, therefore they would incur a high transforming potential.

Figure 4 represents the integration of $\mathrm{AI}$ and several digital technologies including the ones introduced above. This integration lays down a holistic AI system workflow ranging from the acquisition of data with $3 \mathrm{D}$ technologies; to the visualization of the results with augmented reality of virtual reality. The diagram also depicts the need for storing, transmitting and even distributively performing computations upon data. Moreover, the technologies whose combination enables the implementation of digital twins and smart territories systems, are likewise underlined.

\subsection{Trends in the use of Al and digital technologies for the SDGs}

There exist a relevant number of publications that integrate $\mathrm{AI}$ and other digital technologies for tackling the targets of the SDGs. Accordingly, we have conducted a broad literature review of those publications in order to (i) provide a general picture of how AI and digital technologies can contribute to reach the SDGs, and (ii) highlight promising trends and challenges in using AI for attaining the SDGs, as later described in Section 4.

We organized the literature review in three stages, as depicted in Fig. 5 along with its resulting contributions presented in the remainder of this paper. The first stage consisted in identifying relevant publications related to the application of AI and digital technologies to the SDGs. The second stage involved matching those publications to their target SDG, and the third stage consisted in categorizing those publications into scientific papers and dissemination 
Fig. 4 Representation of the cooperation among AI and other digital technologies for fostering the achievement of the SGDs

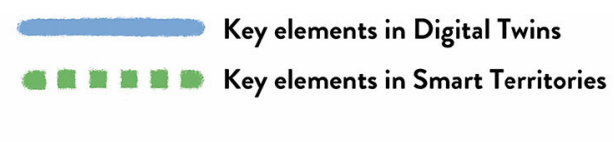

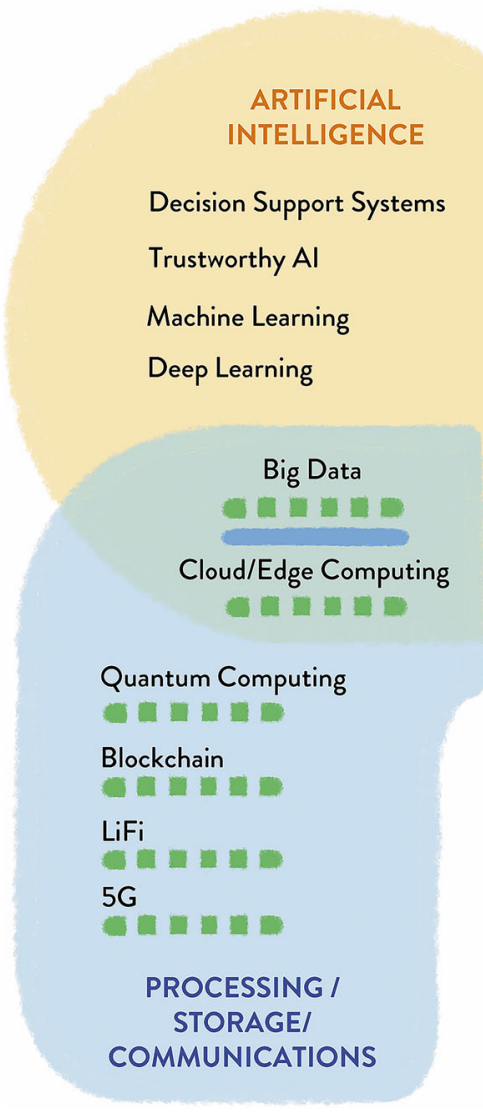

DATA ACQUISITION

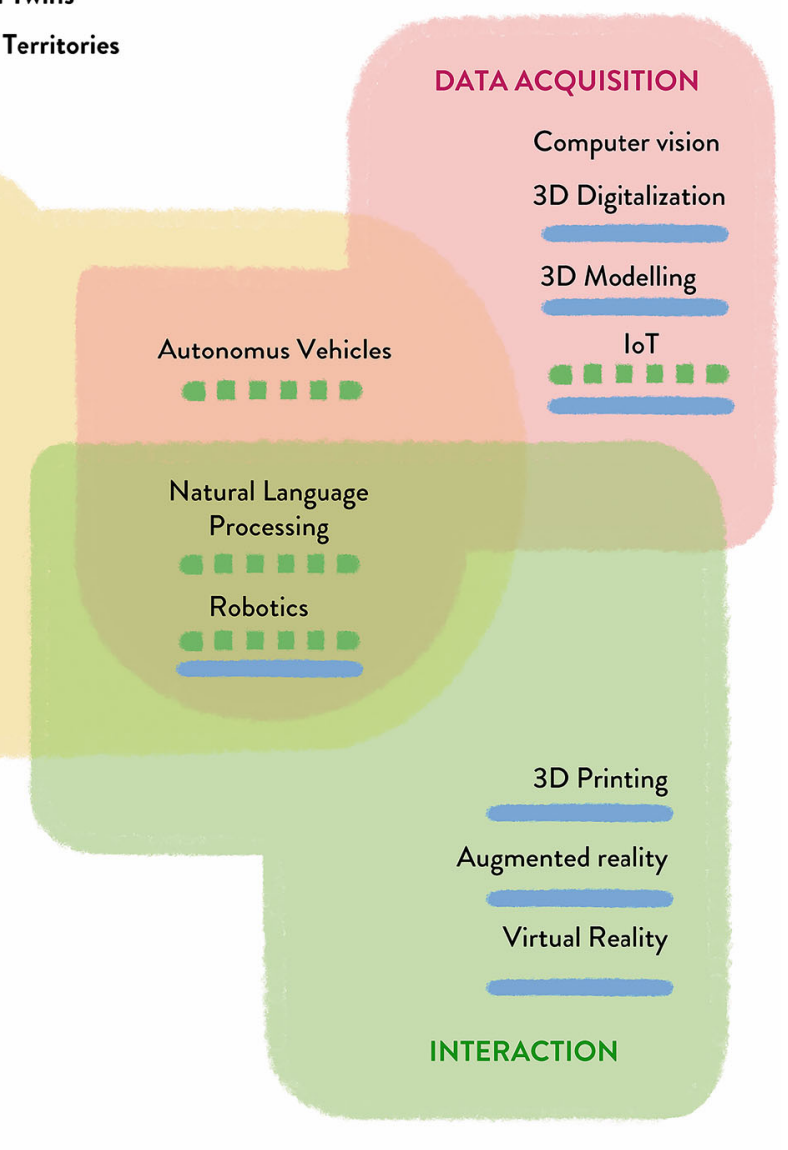

Computer vision

papers. The result is a review composed of 869 publications, whose references are provided as supplementary material for this study in spreadsheet format. ${ }^{3}$ Figure 6 depicts the number of works surveyed in the literature review, classified by type of publication and target(s) SDG -or underlying target to a goal-addressed.

In addition to the above 869 publications that put their lens on specific goals or targets within the 17 SDGs, there also exist a number of studies with a broader focus [1116], which provide a more general view of the challenges, implications and benefits of the joint application of AI and digital technologies to the SDG framework as a whole. Given their relevance to the scope of this study, below we succinctly review these works as follows:

Goralski and Tan, 2020 [11]. Their study investigates whether the application of AI based services can accelerate the achievement of the SGDs. The analysis is accompanied by three case studies, namely: (1) smart water management, (2) the use of AI in agriculture and (3) the use of AI in sanitation services as the clean water

\footnotetext{
${ }^{3}$ https://github.com/ari-dasci/OD-AI-SDG
}

provision system. As a result, the authors assert that AI can contribute to:

1. Improve the efficiency of industrial processes.

2. Preserve nonrenewable resources.

3. Help disseminate expert knowledge.

4. Reduce the gap among resources and technology.

5. Foster the creation of alliances among governments, the private sector and the society for maximizing global sustainability.

Moreover, they point out that the implementation of AI requires planning and collaboration for harnessing the benefits of $\mathrm{AI}$ and minimizing its risks.

Truby 2020 [12] In this study, the author expounds that AI has the potential to be vastly positive driver to reach the SDG, but technological companies might also hinder this potential. For this reason, he advocates a regulatory strategy of AI that ensures the development of verifiable, accountable and transparent AI systems. Moreover, Truby proposes that countries that signed up the SDGs agreement could refuse to adopt technology that does not comply with basic SGD principles. 


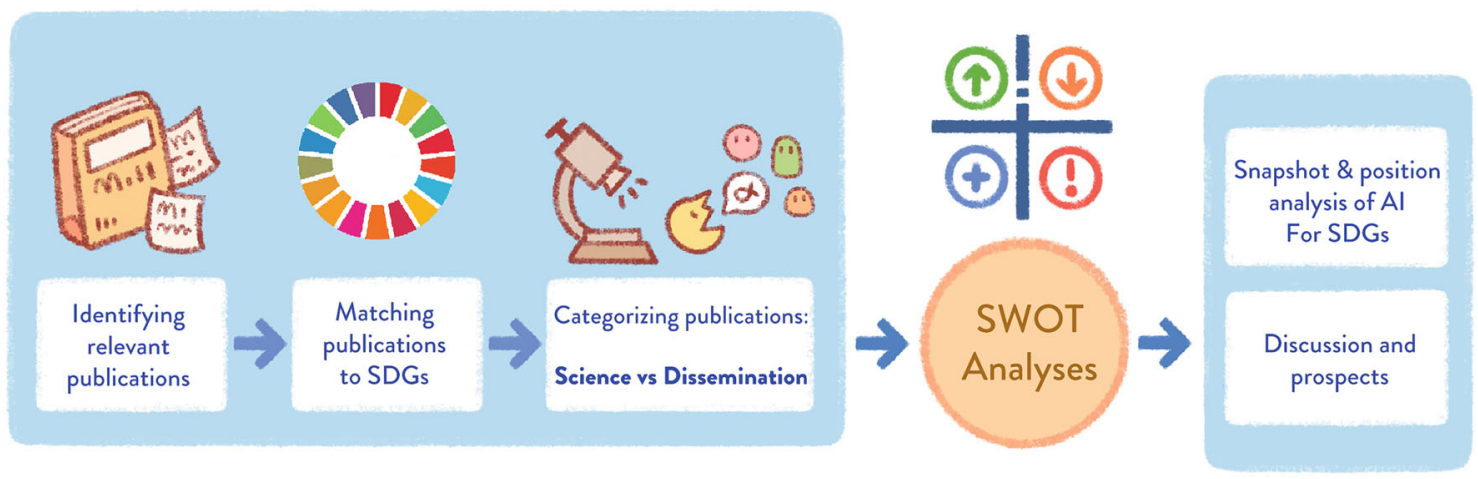

Fig. 5 Stages of the literature review as an input to the contributions of this study

Nguyen 2016 [15] and Zwitter and Herman 2018 [16].

These two works are focused on the contributions of blockchain technology to various targets of the SDGs. For instance, the applications of blockchain on the financial sector are highlighted in [15], specially on its capacity of tracing data for ensuring its integrity. Likewise, the use of blockchain technology against corruption and for creating secure digital entities is underlined in [16].

Wu et al. 2018 [14] Wu et al. identifies the economic, social and environmental challenges of applying AI for pursuing the SDGs in [14]. For instance, the authors highlight the importance of using personalization methods for adapting or recommending teaching materials in e-learning scenarios. Likewise, they propose holistic conceptual architectures that represent how data from

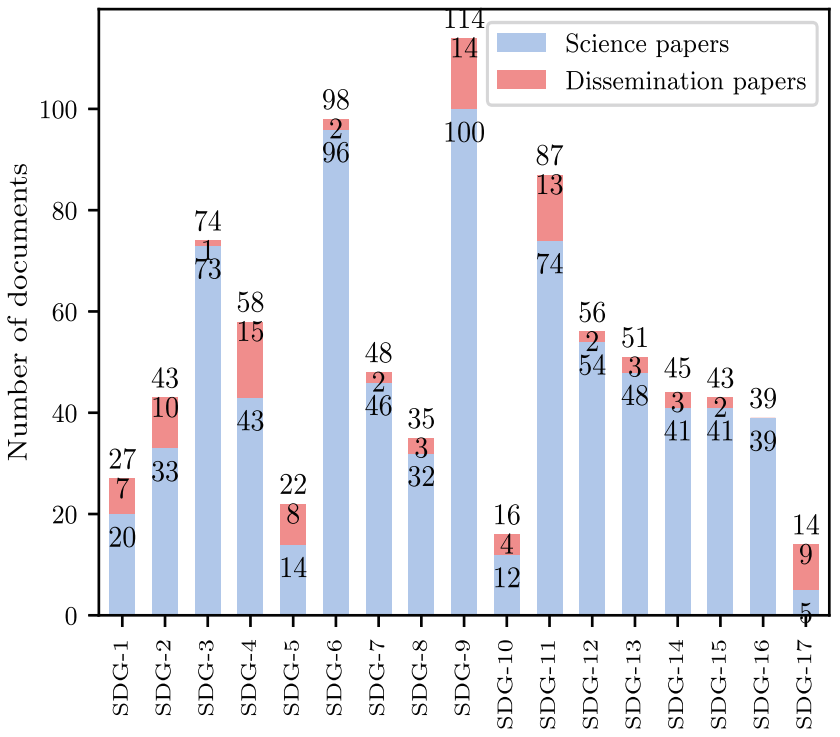

Fig. 6 Number of documents reviewed per scientific and dissemination category different sources may interact with IoT devices and AI methods for the different perspectives of the SDG. The authors conclude that $\mathrm{AI}$ and digital technologies have a great potential to support global economical, social and environmental sustainability.

Vinuesa et al. 2020 [13]. The authors assess, by means of a consensus-based opinion elicitation process at a collective level, the effect of using AI-based services for attaining the SDGs. The evaluation indicated that AI services can uplift the $79 \%$ of the targets of the SDG, while it can hinder the $35 \%$ of the targets, thereby leaving a small number of "overlapping" targets (14\%) where AI could be both enabler or barrier to the goal(s) depending on the specific uses given. Hence, the application of AI could be more beneficial (and its risks could be minimized) by a right regulation of its implementation. For instance, social media applications currently provide a wealth of information to users, whose veracity is not previously verified in most cases. This may consequently lead to socio-political polarization between users of those social media platforms, which in turn may provoke political and social tensions. By contrast, some AI methods based on natural language processing may positively help to identify misleading information published on social media [36].

A central idea underlying the previous works is the importance of the interactions among AI, the society, environment, the economy and the government. These interactions are depicted in Fig. 7, and they evidence the need for approaching these critical interactions from a global perspective with the guidance of solidly established regulations, as Vinuesa et al. expound in [13]: "as society is constantly changing (also due to factors including nonAI-based technological advances), the requirements set for AI are changing as well, resulting in a feedback loop with interactions between society and AI" [13]. The environment also partakes in these interactions by providing 
Fig. 7 Interaction between AI, society and environment. Inspired by [13]

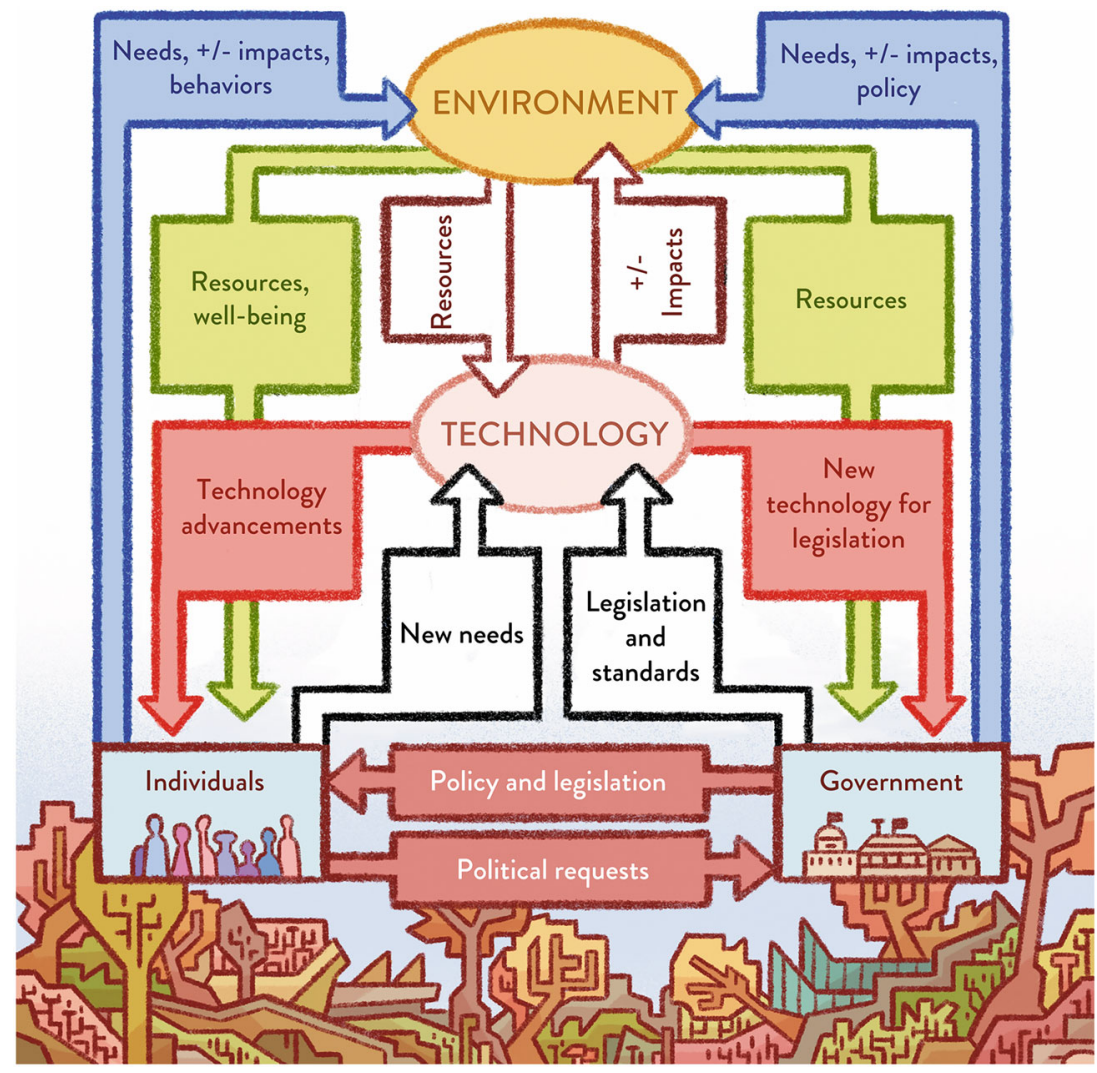

the required resources for development and being affected by the environmental impact of developed technology as well as individual and government actions.

\section{A snapshot, SWOT and position analysis of artificial intelligence and digital technologies for the SDGs}

This section provides a snapshot-style position analysis of the role that AI-driven technologies can play in the pursuance of the SDGs, highlighting the opportunities and potential contributions that these technologies can bring as enablers for sustainable development. The below discussion focuses on prospects, i.e. recommendations for an aligned use of such technologies with sustainability. These recommendations are founded on a series of SWOT analyses made upon the literature surveyed, as explained in Section 3.3.

Remark 1 In previous sections, it has been shown that AI is closely tied to other digital technologies, which are indispensable for instance to perceive, interact with and understand the environment, acquire and storage data, etc. Notwithstanding, in order to avoid excessive repetitions and simplify the discussion, the use of the term ' $A I$ ' should be understood hereinafter as its general integration or combined application with other digital technologies (see Fig. 4).

The analysis is organized according to the six perspectives of human needs considered in the study:

- Economic dimension: life (Section 4.1).

- Economic dimension: economic and technological development (Section 4.2).

- Social dimension: social development (Section 4.3).

- Social dimension: equality (Section 4.4).

- Environmental dimension: resources (Section 4.5).

- Environmental dimension: natural environment (Section 4.6).

For convenience of discussion, the results of the SWOT analyses -one per SDG- are provided in tabular format over the course of the following subsections.

\subsection{Analysis for the economic dimension: life}

The three SDGs under the life perspective are the most closely linked ones to human welfare, concretely the goals that pursue ending poverty (SDG 1), eradicating hunger (SDG 2) and enhancing good health and well-being (SDG 3). Based on the SWOT analyses made for these three goals (Tables 2, 3 and 4), Fig. 8 lists some recommendations on how AI can help achieving these long-desired goals. 
Table 2 SWOT analysis of the SDG 1: No Poverty

\begin{tabular}{ll}
\hline Strengths & Weaknesses \\
\hline
\end{tabular}

- Emergence of new technologies in primary and industrial sector across developing countries.

- Predictive power of machine learning upon satellite and aerial images.

- Deep Learning with mobile device data as a strong domestic income predictor.

- Combining digital transaction and property data in regression techniques.

Opportunities

- $\mathrm{AI}$ and digital technologies support government decision-making against economic breach.

- Identifying how AI advances spread globally to ensure equal development.

- Digital labor and outsourcing for employment.

- Blockhain for transparent and corruption-free government processes.

- Passive data collection bridged with AI and data analysis for reliable poverty estimations.
- Shortage of relevant data to measure poverty in developing countries.

- Institution costs to actively collect data for measuring poverty.

- Determining appropriate thresholds for poverty level classification tasks.

- Institutional corruption and instability as obstacles to economic prosperity.

Threats

- Automation processes accentuate rich-poor breach and economic disparity.

- AI-driven automation could affect low-salary labor workforce.

- Higher economic disparity risk due to technologically globalized trade.

- Dependence on other nations if no pathways for AI breakthroughs are identified nationwide.
The fight against poverty and hunger is intimately related to fair and transparent government systems [37, 38]. The accomplishment of these two qualities, fairness and transparency, can be enabled through systems capable of trac- king data logs transparently: something possible nowadays thanks to blockchain technologies [39]. Likewise, AI systems may facilitate more appropriate decisions predicated on such tracked data logs [40]. Taking a closer glance, it can

Table 3 SWOT analysis of the SDG 2: Zero hunger

Strengths Weaknesses

- Partnerships between organisms and technological firms lead to better solutions to identify areas under (or prone to) hunger using AI.

- Combining demographic and socio-economic information with satellite data to predict famine, crop diseases/plagues or demands after disasters.

- Optimization and sequential decision-making algorithms help managing the Water-Energy-Food Nexus to guarantee food sustenace.

Opportunities

- Robotics to facilitate and automate stockbreeding.

- AI-based early warning systems to give rapid and life-saving response to extreme famine situations.

- Big data applications in smart farming approaches for efficient farm production and food provision.

- Blockchain to optimize supply-demand, prevent food waste and fraud alongside smart packaging.

- Government policies founded on digital technologies that support small farmers.

- Drones for enabling smarter farming processes.
- Poor famine and harvest predictions without sufficient temporal data from multiple sources.

- Sensitivity of soil or plant disease classification models when used in isolation.

- Little advances in using AI to promote sustainable and healthy eating behaviors in the population.

- Lack of accessible open data for farming and climate phenomena prediction.

Threats

- Incorrect famine predictions in vulnerable households and highly heterogeneous areas.

Uncontrolled advances in AI-based farming technologies may accentuate breach between small and large-scale farmers.

Sharing big data to foster intelligent farming practices may be subject to appropriation and abuse of such data.

AI applications without solutions for risk anticipation may compromise global food security. 
Table 4 SWOT analysis of the SDG 3: Good health and wellbeing

Strengths $\quad$ Weaknesses

- Predictive machine learning is a valuable tool for various medical prognosis and diagnosis tasks.

- Data-driven interpretable decision support systems for intensive care, including neonatal children.

- Deep learning on medical image data brings revolutionary advances in medical predictions.

- Machine learning with big data and expert judgement drives advances in biomedicine.

- AI to manage limited health resources in rural areas.

Opportunities

- IoT-driven smart environments for elderly care.

- AIDS prevention via trend analysis in social media.

- Mobile devices, sensors and social media in smart territories for early detection epidemic diseases.

- Wearables for activity tracking and data logging.

- Personalization and recommender systems against tobacco use and to promote healthy habits.

- AI for precision medicine and vaccine development.

- Training health staff on trustworthy AI for better decision-making.
- Predicting cardiovascular or air pollutant factors demands continuously collected data.

- Arbitrariness of human driver movements and pedestrians stunts accident prediction by AI.

- Chatbots for sexual health awareness lack public acceptance.

- Automation of drug development prone to errors without human supervision.

Threats

- False positive predictions in high-risk pregnancy or cancer detection may accentuate mortality rates.

- Privacy of individuals endangered by social media-based solutions to prevent suicides.

- Excessive use of AI tools in surgical processes might cause loss of human skills.

- Ethical AI dilemmas on "whom to blame" upon fatal decision outcomes. be stated that blockchain can turn food production processes more effective, transparent, traceable and sustainable, reducing food loss and waste, and guaranteeing food security [41]. Besides, the capacity of digital technologies and AI systems for data acquisition, fusion and analysis would assist decision-making processes linked to food production, transport and consumption, making these complex decisions as fair and balanced as possible [42, 43]. Meanwhile, the descriptive and predictive power of AI, concretely machine learning algorithms, will permit identifying and forecasting areas under (risk of) poverty, thereby facilitating the implementation of timely actions for their eradication [44-47], as
Fig. 8 Recommendations on using $\mathrm{AI}$ in the SDGs of economic dimension: life

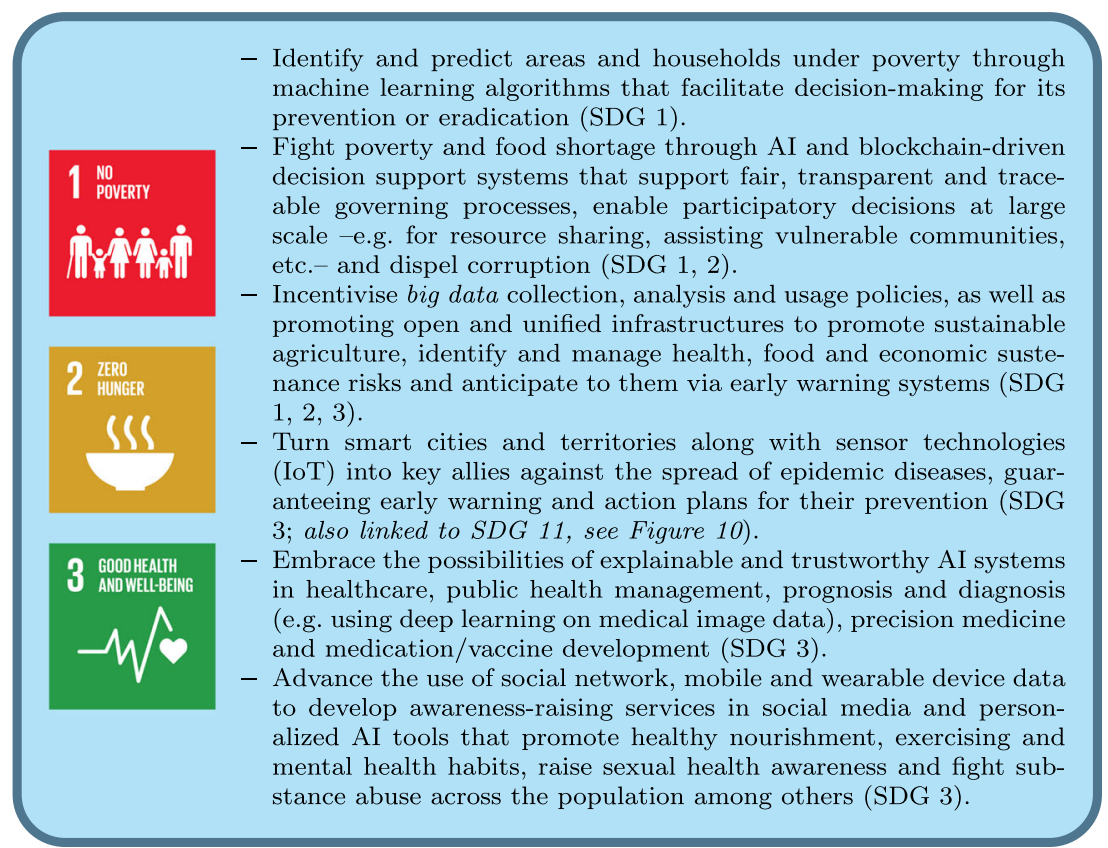


well as enabling smarter and more sustainable farming processes for enhanced food production, predicated on big data, sensors and IoT technologies [48].

AI has emerged with particular strength in the medical domain over the recent years, where there are prolific proofs of its advances, strengths and opportunities in prognosis, diagnosis, healthcare or preventive medicine [49-53]. Besides, AI can be applied in the public health landscape by leveraging social network and Web 2.0 media data, which in turn can be exploited to control drug abuse [54, 55], toxic substance consumption [56], sexual and reproductive health [57], as well as healthy life habits [58-60]. These data, along with those provided by wearable devices, constitute another valuable information source for developing personalized recommender systems to promote healthy habits and support better individual decision-making in terms of healthy choices [60-62]. Nonetheless, the prioritization of trustworthy AI systems [26] must become imperative in these domains.

The COVID-19 pandemic has evidenced the urgent need for digital technologies and AI-based models to address the public health management challenge that a global pandemic poses [63, 64]. Such technologies have been reported as effective tools to control the spread of the disease via contact tracing processes amongst infected and healthy people alike, and IoT sensors in smart cities/territories would have a key preventive role in the near future [65]. Inspired by recent examples of nations that have successfully kept the virus transmission under control, a glance should be put on the union between mobile technologies, sensors, smart territories, AI and big data as a joint instrument for control, early warning and knowledge-guided ${ }^{4}$ decision making against epidemic risks, underpinned by real-time infection traceability. Meanwhile, controlling any large-scale epidemic also demands an efficient management of healthcare system resources [51, 66]. AI models can be used in these scenarios to predict the evolution of infections with the aim of foreseeing medical protection supply, hospital bed and intensive care needs [53, 66, 67].

\subsection{Analysis for the economic dimension: economic and technological development}

Whilst SDGs under the life perspective relate to human life sustenance (poverty, hunger and health), the SDGs under the economic and technological perspective are associated to key involved elements to achieve such sustenance: work (SDG 8) and developments in working environments (SDG 9). The literature analysis of these goals shows that the industrial application of AI has brought added challenges -digital breach and its associated unemployment risk [11,

\footnotetext{
${ }^{4}$ Knowledge should rely on the dialogue between scientists and governments, see Section 5.
}

68]- to existing ones, such as salary breach between qualified and unqualified workers, overuse of raw materials and the resulting contamination from industrial processes [6972]. Notwithstanding, the adequate utilization of the advantages brought by AI under suitable courses of action may help largely overcoming the aforesaid challenges.

Figure 9 sums up the main prospects that can be distilled from the SWOT analyses of SDGs 8 and 9 (see Tables 5 and 6). Some remarkable examples of these prospects and recommendations - proposed as guidelines for institutions and companies for their development as action plans- are discussed below.

The rising need for fostering high education and formative itineraries under a scientific-technical or STEM ${ }^{5}$ (Science, Technology, Engineering and Math) profile [74, 75] would signify a potential opportunity to alleviate the digital breach across professional sectors, improve employability driven by innovation, enhance professional mobility and ultimately support economic prosperity. The importance of such formative itineraries should not only be understood as a central tool to fight the digital breach, but also underlined across sectors of the population that have historically had more difficulties to access them and, ultimately, as a means to safeguard vulnerable employees whose jobs/tasks might be potentially replaced by algorithms or robots. Meanwhile, promoting added-value and innovative AI developments could be deemed as an effective approach to generate new labour tasks and subsequently new jobs, in replacement to those potentially lost due to the automation [76].

More attention is needed in focusing electronics production on highly controlled recycling policies [4, 77] and, in general, aligning 3D printing processes with waste and pollutant minimization as a result of them. In this sense, blockchain could be used as a digital auditing and traceability resource for managing raw materials in electronics, concretely minerals such as tantalum, tin, tungsten, gold, etc. A transparent tracking of such materials along their life cycle could significantly ease their recycling and posterior use.

There are also multiple prospects related to sustainable innovation and industrial processes. One of them consists in providing support to innovation startups and $\mathrm{SMEs}^{6}$ with promising innovation initiatives for the digital transformation of economy and Industry 4.0 [1, 78]. Smart contracts, on the other hand, could enforce policies aligned with contaminant reduction, specially if this line of action is aligned with the advantages of AI to automate and make penalty

\footnotetext{
5The STEM gap: https://www.aauw.org/resources/research/the-stemgap/

${ }^{6}$ SME: Small or Medium Enterprise.
} 
Fig. 9 Recommendations on using $\mathrm{AI}$ in the SDGs of economic dimension: economic and technological development
- Promote strongly scientific and technical (STEM) formative itineraries in higher and postgraduate education to alleviate the so-called technological unemployment (SDG 8; also linked to SDG 4, see Figure 11)

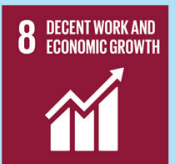

Foster added-value AI initiatives based on innovation in conjunction to (or as replacement to) automation ones to keep a balance between newly created jobs and jobs replaced by the AI (SDG 8,9 ).

- Distributed offshoring in manufacturing of replacement pieces, by 3D printing processes and blockchain-based models certification, so that both waste production and pollutant emissions due to transportation of repairing pieces are reduced (SDG 8, 9).

- Catalyse the AI-based digital transformation of the economy, supporting the development of Industry 4.0 concepts specially in SMEs (SDG 9).

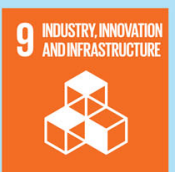

- Develop and deploy complex systems that combine IoT, big data, blockchain and predictive AI systems to monitor and certify pollutants, specially in industry and transportation (SDG 9).

- Use smart contracts for reinforcing contaminant reduction commitments of nations, so that penalties can be automatically applied [67] (SDG 9).

- Drive R\&D project evaluation processes guided by AI, to detect potential impact of industrial and innovation processes and promote the funding of those with higher environmental, economic or social revenue (SDG 9). processes against infractors more efficient. [73]. Achieving a larger presence of IoT and big data in industrial environments and transportation infrastructure is another mandatory step to take, in order to enforce highly controlled pollutant reduction [5, 9, 79-82]. Lastly, in the scientific landscape, it would be beneficial to stimulate $R \& D$ project evaluation processes guided by AI, so as to detect potential impact of industrial and innovation processes and, consequently, foster the financial fund of those initiatives with stronger environmental, economic or social implications in their proposed activities and portfolio [83].

\subsection{Analysis for the social dimension: social development}

As pointed out in the previous section, the economic dimension focuses on individual-centered aspects, whereas the social dimension considers relationships between people and communities. Accordingly, the social development

Table 5 SWOT analysis of the SDG 8: Decent work and economic growth

\begin{tabular}{|c|c|}
\hline Strengths & Weaknesses \\
\hline $\begin{array}{l}\text { - New STEM jobs in the third sector for better resilience against } \\
\text { economic crises. }\end{array}$ & $\begin{array}{l}\text { - Replacement of non-qualified workers by robots or algorithms in } \\
\text { least developed countries. }\end{array}$ \\
\hline $\begin{array}{l}\text { - Personalized advertisement in social media increase access to job } \\
\text { opportunities. }\end{array}$ & $\begin{array}{l}\text { - Accentuated breaches under non-regulated AI implantation in } \\
\text { professional contexts. }\end{array}$ \\
\hline $\begin{array}{l}\text { - Smart cities and intelligent transportation systems propel efficient } \\
\text { commuting and flexible working. }\end{array}$ & $\begin{array}{l}\text { - Current studies of AI impact on work dismiss its potential } \\
\text { expansion in some applications. }\end{array}$ \\
\hline $\begin{array}{l}\text { - Lowering sensor costs and Open Data enable access and } \\
\text { application of AI in more sectors. }\end{array}$ & \\
\hline Opportunities & Threats \\
\hline $\begin{array}{l}\text { - Digital labor and external outsourcing as an engine to create } \\
\text { employment. }\end{array}$ & - Increased inequalities by emergence of AI and robotics in work. \\
\hline $\begin{array}{l}\text { - Mobile technologies enable universal access to e-commerce and } \\
\text { secure online banking. }\end{array}$ & $\begin{array}{l}\text { - Limited access to learning and education aggravates professional } \\
\text { polarization. }\end{array}$ \\
\hline $\begin{array}{l}\text { - Ambient intelligence, IoT and machine learning to anticipate job } \\
\text { accidents in risk contexts. }\end{array}$ & - Labor tasks replaced by AI give rise to cyber-crime opportunities. \\
\hline $\begin{array}{l}\text { - Crop and assembly chain digitisation are transforming agriculture } \\
\text { and food manufacturing. }\end{array}$ & $\begin{array}{l}\text { - Uncontrolled rise of remote working might imply psychological } \\
\text { and work organization risks. }\end{array}$ \\
\hline $\begin{array}{l}\text { - Expert prognosis systems in drones for maintenance of critical } \\
\text { resources at work. }\end{array}$ & $\begin{array}{l}\text { - Some materials needed in AI and IoT chips, e.g. coltan, rely on } \\
\text { child slavery for their production. }\end{array}$ \\
\hline
\end{tabular}


Table 6 SWOT analysis of the SDG 9: Industry, innovation and infrastructure

Strengths $\quad$ Weaknesses

- Intelligent sensors and 5G for real-time infrastructure monitoring.

- Environmental factors in complex settings affects quality of 3D laser modelling.

- Remote computer vision and 3D models to detect anomalies and facilitate maintenance.

- Lack of scientific standards to validate digital 3D models for their use as digital twins.

- Edge computing, 5G and sensors draw safe autonomous vehicles closer to reality.

- Absence of integrated data platforms hamper the use of intelligent systems for infrastructure design.

- Robust traffic prediction with neural networks.

- Automatic systems for efficient route planning.

- Most traffic prediction systems neglect environmental and social context data.

- Discordance between quality indicators for scientific production and innovation.

- Natural language processing automates design and tracking of protocols and contracts.

Opportunities

Threats

- 3D concrete printing and offsite construction lower environmental impact and may reduce costs.

- AI for designing environmental risk maps helps recovering from disasters.

- IoT, big data and computer vision to jointly improve predictive infrastructure maintenance.

- Intelligent optimization systems for more sustainable transport and logistic systems.

- Industry 4.0 supports emergence of small, medium enterprises and startups anywhere.

- Intelligent traffic management might increase use of private vehicles against public transport.

- Railway traffic renovation entails high infrastructure change costs.

- Industry 4.0 brings socio-economic risks in developing countries due to job losses.

- The reluctance of governments and companies to openly report pollutant emissions hinders developing AI prediction and warning systems.

- The lack of shareable open data in science impedes the flourishing of automatic R\&D assessment and publication access by developing countries.

- Smart factories for sustainable and inclusive innovation in developing regions.

perspective attends to the areas where people live, namely sustainable cities (SDG 11); political organization and solid institutions (SDG 16); and cooperation pathways between social organizations through partnerships to achieve the goals (SDG 17). Figure 10 blends the most noteworthy recommendations extracted from the literature review and the associated SWOT analyses for these three goals -the latter of which are summarized in Tables 7, 8 and 9.
Fig. 10 Recommendations on using AI in the SDGs of social dimension: social development

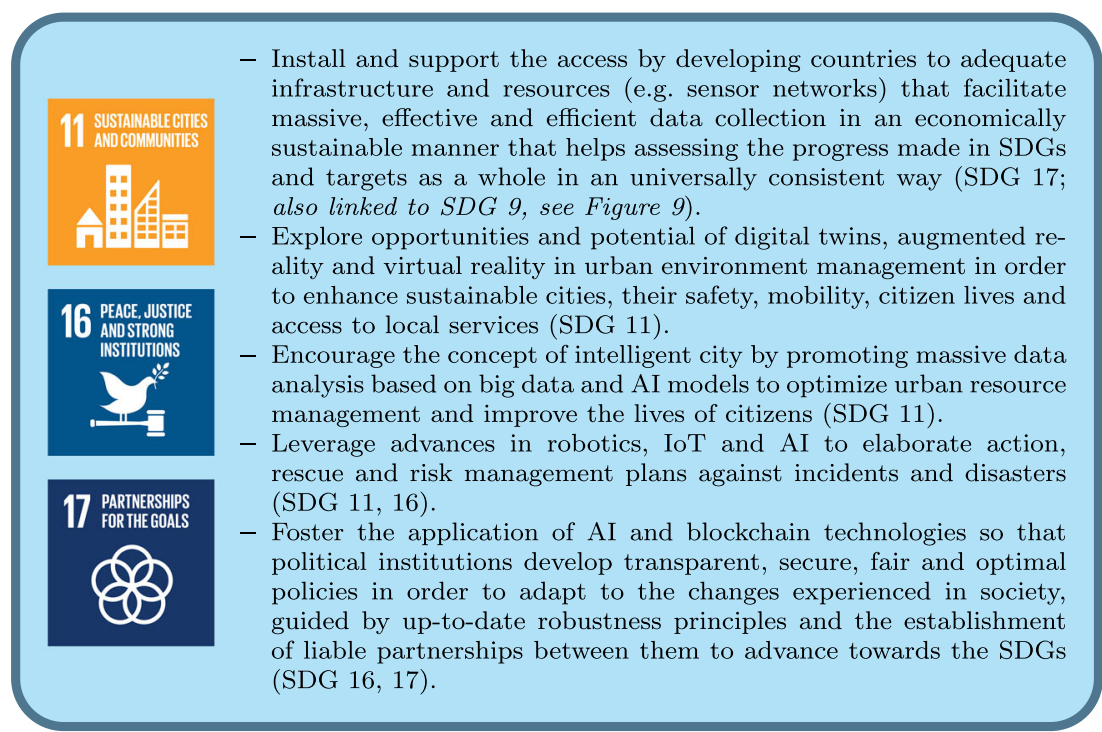


Table 7 SWOT analysis of the SDG 11: Sustainable cities and communities

\begin{tabular}{ll}
\hline Strengths & Weaknesses \\
\hline - Intelligent personal assistants, sensing multi-functional drones & $\begin{array}{l}\text { - Open-AI paradigm regulations insufficiently extended, owing to } \\
\text { lack of information exchange. }\end{array}$ \\
$\begin{array}{l}\text { and autonomous vehicles are significantly facilitating citizen lives. } \\
\text { optimize essential supplies in cities. }\end{array}$ & - AI models generally do not self-adapt to data in real time. \\
- Context-aware decision-making algorithms give insight to city & - Low number of citizen-centered initiatives. \\
authorities. & - Human behavior is difficult to model in traffic event prediction. \\
- Sentiment analysis to mine public opinion and improve urban & \\
services through their participation. & $\begin{array}{l}\text { - Fusing new and traditional data sources demands modernizing } \\
\text { - AI to optimize and make transport flexible. }\end{array}$ \\
Opportunities & Threats
\end{tabular}

- Radar, positioning and video surveillance technologies to control traffic congestion and regulation.

- Integrating AI in urban design and planning guided by egovernment.

- Video surveillance for heritage and nature preservation.

- Information systems for real-time public awareness on the impact of products/services used.

- Earth observation combined with other big data sources to create highly precise digital twins.
- Barriers to bridge gaps between public and private institutions and achieve data interoperability.

- The non-ownership of Internet impedes the creation of worldwide regulations against digital threats.

- Electro-mobility sector and future demand by new generations need further investigation.

- Society may refuse to accept decisions made by autonomous systems and vehicles as legitimately as human decisions.
The application of AI has led some cities to thrive in their digitisation processes [84-86], turning them into more sustainable environments where the available resources are leveraged more intelligently. Even so, there still remain large urban areas that have not made sufficient progress in such digitisation, deeming this process as an unaddressed challenge as of today.
Cities are complex environments whose management demands taking a great deal of variables and factors into consideration [87]. Digital twin technologies enable the tracking and monitoring of urban processes in all their forms [33, 88, 89], thereby facilitating optimal transportation systems [90] as well as unveiling areas for improvements in energy, food and water supply. As a result, a more

Table 8 SWOT analysis of the SDG 16: Peace, justice and strong institutions

Strengths $\quad$ Weaknesses

- Data mining on credit card transactions for fraud detection.

- AI to improve predictive power in public corruption detection.

- AI is key for crime prediction, diagnosis and autonomous decisions on crime at little cost.

- Electronic platforms to access justice and provide judicial cover to all communities.

Opportunities

- Massive increase in e-transactions facilitates data needs for effectively fighting fraud.

- Blockchain and cryptocurrencies as a driving force for secure digital transactions and administrative processes.

- Judicial process simulation improve access to justice.

- Self-adapting expert systems for better decision-making against crime based on real-time data.
- AI helps detecting fraud but still lacks solutions to raise awareness against it.

- Models trained upon regional data for fighting crime might not be generalizable to other areas.

- AI along with Internet and social media could accentuate globalized views that compromise diversity.

Threats

- A wrong use of AI for fighting fraud could aggravate it and reval new security breaches.

- AI might cause bias against certain collectives in crime prediction tasks.

- The AI-data binomial could nowadays constitute a tool for intentional manipulation of people's will with different aims. 
Table 9 SWOT analysis of the SDG 17: Partnerships for the goals

\begin{tabular}{|c|c|}
\hline Strengths & Weaknesses \\
\hline $\begin{array}{l}\text { - Defining government strategies based on expert recommenda- } \\
\text { tions on the use of AI systems helps disseminating their correct } \\
\text { implantation. }\end{array}$ & $\begin{array}{l}\text { - Public negative reactions and ethical dilemmas hinder the } \\
\text { consolidation of AI standards. }\end{array}$ \\
\hline \multirow{3}{*}{$\begin{array}{l}\text { - Public initiatives and projects are notably helping to raise citizen } \\
\text { awareness toward a common, global and shared vision of people- } \\
\text { centered and ethical AI. }\end{array}$} & $\begin{array}{l}\text { - Impact and ethical dilemmas of AI in critical and daily contexts } \\
\text { is difficult to assess. }\end{array}$ \\
\hline & $\begin{array}{l}\text { - Professionals in sectors such as finance might be reluctant to use } \\
\text { AI to govern their processes. }\end{array}$ \\
\hline & $\begin{array}{l}\text { - Shortage of earth observation data and acquisition resources } \\
\text { hinders data-centered partnerships. }\end{array}$ \\
\hline Opportunities & Threats \\
\hline
\end{tabular}

- Supranational partnerships to sit standards for trustworthy AI as a powerful global vehicle for a correct use of its innovations at different development contexts.

- 'Best practices' frameworks on accountable AI focused on impact of algorithms to strengthen partnerships on using AI to achieve the SDGs.

- Sitting standards and interdisciplinary partnerships in organizations to reduce AI-related breaches.

- Incentivising wider discussion on the AI-social justice nexus to create competitive sustainable partnerships.

- Create global standards for massive earth observation data usage to pursue the SDGs fairly and constently across nations.
- Algorithmic decisions may sometimes impact negatively on disadvantaged communities.

- Some indicators underlying SDG targets may neglect potential benefits of using collected earth observation data, which motivates making such indicators more flexible and proposing alternative ones for a more realistic measurement of SDG attainment. environment friendly management would be yielded along with an improved citizen life quality [91]. Nonetheless, these forecasting and planning processes are not always exempt from errors and subsequent disasters [81]. In these specific scenarios, the blend of IoT and robotics systems may ease the management of the emergency situation itself, providing up-to-date information and reducing human intervention in hazardous contexts and preventing human accidents thanks to the use of robots [92-94]. It is likewise important to make optimal use of urban resources and enhance services accessed by citizens in their daily lives: something where the concept of smart city underpinned by $\mathrm{AI}$ and big data shall become the norm.

On the other hand, institutions are the cornerstone element that underpins the main social organizational structure in any nation: the state. In order that states are resilient and they can establish trustworthy partnerships with each other, they necessitate solid institutions on which commitments are founded [95]. The robustness of institutions lies not only in their trustworthiness, but also in their representative power and potential for participation by the societies they are meant to serve [96, 97]. This makes it imperative for them to develop fair, transparent and effective government schemes that are free from any form of corruption [98-100]. Combining big data and blockchain may drive a transparent, traceable and massive data analysis to support appropriate decision-making in complex decision scenarios raised in national and supranational institutions. Particularly the blockchain will strongly contribute to assure robust and traceable financial transactions and, in general, banking operations, hence stretching the room for the crime. Improved decision-making and management capabilities supported by ethical and accountable AI [101] will result in strengthened institutions, a higher trustworthiness between them, and a noticeable momentum towards the attainment of the SDGs as a whole [102, 103]. Developing and disadvantaged countries must not be neglected and should be particularly supported in these efforts, e.g. by facilitating them resources for massive data collection.

\subsection{Analysis for the social dimension: equality}

The social dimension of the SDGs also concerns itself with ensuring inter-personal relationships under terms of equality in all its forms. Consequently, the equality perspective includes goals related to access to education (SDG 4), gender equality (SDG 5) and reducing inequalities (SDG 10). Figure 11 highlights the main recommendations resulting from the literature and SWOT analyses undertaken 
Fig. 11 Recommendations on using AI in the SDGs of social dimension: equality

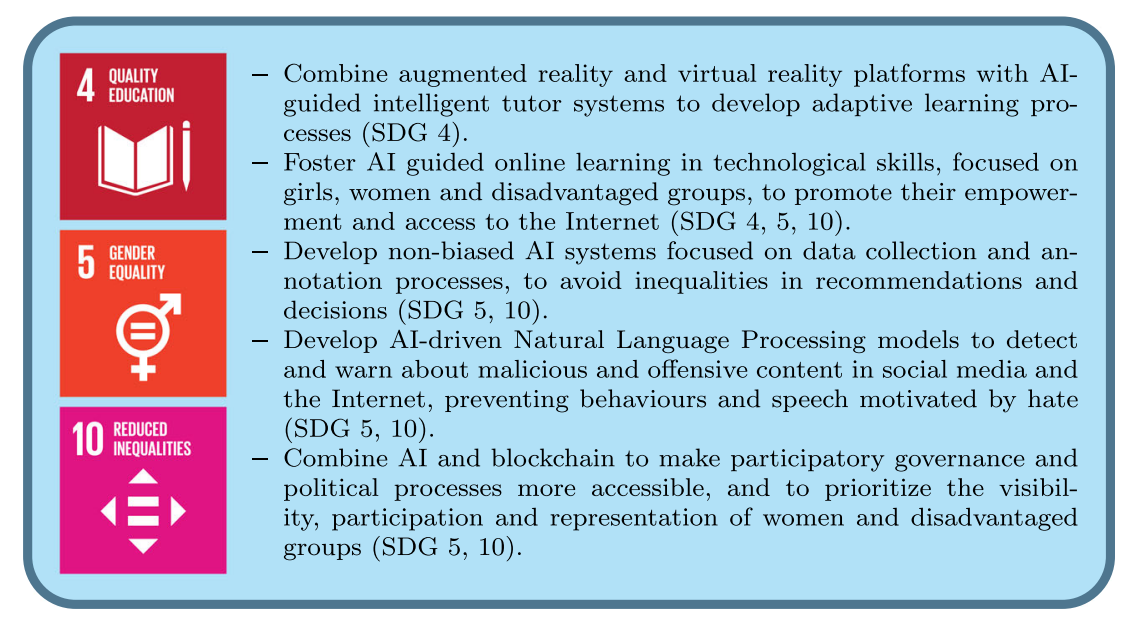

in accordance with these goals. These analyses are shown in Tables 10, 11 and 12 .

Education is the core resource to drive prosperity among people, being categorized as a "social elevator" [75, 104, 105]. For this reason, it is paramount to guarantee access to quality education for the entire population. Expanding education access even to the innermost corners and the most vulnerable collectives requires fostering the total integration of Internet, cloud distributed technologies, AI and augmented reality in educational systems, with a twofold aim [106, 107]. Firstly, to create virtual learning platforms permitting the use of varied teaching methodologies that adapt to the individual learners' needs [108], endowed with intelligent tutoring systems [109, 110]. Secondly, to offer education opportunities not only for people with limited availability for physical on-site learning, but also for disadvantaged groups and women in least developed countries [111]. On another note, the access to learning tools by small and medium enterprises should not be ignored [112], so that they can undertake the indispensable process of digital self-update to adapt to changes driven by the current technological revolution.

A quality education is also fundamental for the flourishing of societies where individuals are deemed as equal regardless of their race, gender, beliefs, opinion, sexual orientation or any other condition, personal or social circumstance $[113,114]$. Yet, the value of equality at its highest, reflected in most legislation codes worldwide, must be materialized in everyday individual behaviors. As a man-made product, AI systems should not be exempt from respecting equality values, hence investments and efforts are needed to avoid any bias that may violate such principles and values in these systems [115-117]. It is therefore crucial to foster research and work towards defining data compilation and annotation standards that prevent any biased trends, because non-biased data would make it easier to ensure AI systems that preserve equality values and abide to trustworthiness principles. Furthermore, there exist initiatives to empower discriminated communities, e.g. black communities, ${ }^{7}$ based on the value of data.

AI can be likewise employed to detect behaviors that violate equality principles. An obvious scenario of application in this sense is social media, whose possibilities for anonymity trigger many individuals to cause intentional offense against other individuals or communities [118, 119]. The use of natural language processing methods can help recognizing inadequate forms of communication, such as hate or extremist speech, making it possible to identify offenders and -where applicable- putting this knowledge at the disposal of legal authorities [120]. Moreover, the sense of freedom that generally governs many Internet sites, particularly social media, gives rise to the dissemination of false contents, namely the well-known fake news and bots, with the intention to propagate hoaxes, lies and fallacies or to create polarization [121-123]. These contents must be detected and amply warned about, not only to prevent their propagation, but also to impede the appearance of discriminatory and unequal behaviors triggered by such contents.

Turning politics/governance and political representative election processes into highly participatory and accessible processes by the general population, clearly constitutes a pathway towards equality [96, 124, 125]. AI together with blockchain have much to offer in improving access to participatory politics and governance where everyone can have their say, owing to their inherent security, transparency and traceability in the use of data, in addition to their potential to support equitable and fair decision-making $[74,126]$.

\footnotetext{
${ }^{7}$ Data for black lives project: https://d4bl.org/about.html
} 
Table 10 SWOT analysis of the SDG 4: Quality education

\begin{tabular}{|c|c|}
\hline Strengths & Weaknesses \\
\hline $\begin{array}{l}\text { - Interactive learning tools supported by mobile apps and } \\
\text { gamification. }\end{array}$ & - Low impact of virtual reality in schools. \\
\hline $\begin{array}{l}\text { - AI-based personalization to provide contents adapted to learners' } \\
\text { individuals needs. }\end{array}$ & $\begin{array}{l}\text { - More attention needed in adapted and location-based teaching } \\
\text { systems to yield equity, efficiency and quality education. }\end{array}$ \\
\hline $\begin{array}{l}\text { - Immersive learning fosters community-level interaction and } \\
\text { resource sharing across disciplines. }\end{array}$ & $\begin{array}{l}\text { - Insufficient training on use of technology and user-computer } \\
\text { interaction in education systems. }\end{array}$ \\
\hline - User-centered software design favors inclusive education. & $\begin{array}{l}\text { - Identifying present and future key competences to ensure lifelong } \\
\text { learning. }\end{array}$ \\
\hline Opportunities & Threats \\
\hline $\begin{array}{l}\text { - Chatbots to promote classroom participation and student } \\
\text { engagement. }\end{array}$ & - Lack of teachers' skills in digital technologies. \\
\hline $\begin{array}{l}\text { - Intelligent tutors scale-up possibilities towards one-to-one } \\
\text { education tailored to the individual, and supporting students with } \\
\text { special needs. }\end{array}$ & $\begin{array}{l}\text { - Equal access to technologies and AI training is still not a universal } \\
\text { right. }\end{array}$ \\
\hline $\begin{array}{l}\text { - Platforms for sharing contents and ideas empower citizens and } \\
\text { drive equality. }\end{array}$ & $\begin{array}{l}\text { - Level of training in AI far below the pace of digital transformation } \\
\text { in society. }\end{array}$ \\
\hline
\end{tabular}

\subsection{Analysis for the environmental dimension: resources}

Having analyzed and proposed a series of recommended actions for all the SDGs related to people at individual and collective level, this section focuses on those SDGs linked to the relationship between people and the resources offered by our natural environment, namely water resources (SDG 6), energy (SDG 7) and responsible consumption (SDG 12). Tables 13, 14 and 15 show the SWOT analyses made for these three goals, and Fig. 12 underscores a number of recommendations on applying $\mathrm{AI}$ in such goals, which are elaborated below.

One of the most consolidated applications of AI is resource and energy management optimization [127-129], thus it is recommended to align this use of AI with sustainable under the perspective analyzed here. Some highly advisable applications include:

- Use of simulation models based on digital twin implementations to prevent the contamination of water resources through a more accurate and effective management of such resources [130,131].

Table 11 SWOT analysis of the SDG 5: Gender equality

Strengths $\quad$ Weaknesses

- Mobile Internet access by women opens up empowerment possibilities.

- Well trained AI systems remove gender bias in recruitment and similar decisions.

- Blockchain and mobile banking for economic women empowerment.

- AI-guided bullying detection may raise privacy concerns.

- Low technology education by women yields dependency on men.

- Biased machine learning without data that intentionally reinforce vulnerable collectives.

- Social media diminishes privacy and intensifies the feeling of being constantly watched.

Opportunities

Threats

- Social media help raise awareness and cooperation among women with common interests worldwide.

- AI detection of dishonest, bullying or harassing behaviors would help mitigating legal laws by providing evidence to prevent fatal consequences.
- Patriarchal family structures in some countries block women empowerment.

- Government control and retaliation against women who oppose the status quo to defend their rights.

- New forms of digital harassment in social media.

- Women losing access to job markets without systems that enforce their digital training. 
Table 12 SWOT analysis of the SDG 10: Reduced inequalities

\begin{tabular}{|c|c|}
\hline Strengths & Weaknesses \\
\hline $\begin{array}{l}\text { - Financial recommender systems help alleviating economic } \\
\text { breach across workers in different sectors via personalized mobile } \\
\text { banking services. }\end{array}$ & $\begin{array}{l}\text { - Historically discriminated communities face more difficulties for } \\
\text { data generation mechanisms that feed fair AI systems to empower } \\
\text { them. }\end{array}$ \\
\hline $\begin{array}{l}\text { - Cyber-security driven by machine learning to detect strategic } \\
\text { manipulation in financial markets. }\end{array}$ & $\begin{array}{l}\text { - Some employment seeking algorithms suffer from hard to remove } \\
\text { biases, specially gender-wise. }\end{array}$ \\
\hline $\begin{array}{l}\text { - Knowledge integration in predictive AI for combating bias in } \\
\text { scenarios such as job seeking. }\end{array}$ & $\begin{array}{l}\text { - Organizations under the influence of large firms face difficulties } \\
\text { to gain competitive advantage in an increasingly globalized and } \\
\text { Internet-driven world. }\end{array}$ \\
\hline Opportunities & Threats \\
\hline
\end{tabular}

- Trustworthy AI as a valuable paradigm to fight discrimination in myriad contexts.

- Digital banking opens opportunities for foreign trade by small firms at less cost.

- AI in corporate contexts to promote social welfare and fair treatment to disadvantaged people.

- Data approaches as a driver for change in black and other discriminated communities.

- Digital platforms to facilitate citizen participation in decisionmaking and governance to ensure integration and inclusiveness of all communities.
- The effect of data-driven approaches aggravating discrimination of some communities signals the need for urgent change in such approaches.

- Automation in work and economic environments is highly prone to accentuate inequalities against vulnerable individuals.

- Social media combined with fake news and bots yield a dangerous trend toward polarization across sectors of society and hate towards belief, ideology, race, sexual orientation, etc.
- Exploit the rapid advances in neural networks and in particular deep learning techniques in prognosis and detection of failure risks in water and energy supply infrastructures and distribution networks/grids [132].

Table 13 SWOT analysis of the SDG 6: Clean water and sanitation

Strengths

- Machine learning to predict weather and prevent drought by planning ahead.

- AI techniques for better modelling and simplification of complex water systems.

- Real-time data provided by IoT systems for water systems management risk analysis.

- Blockchain for reliable and robust water systems.

Opportunities

- Mining great amount of historical data for future failure prediction in water infrastructure.

- Accurate AI techniques to reduce costs and contamination of water systems.

- Virtual reality to ease human intervention in complex water systems and assure quality.

- The boom of IoT in agriculture to make better use of water resources by fine-grained planning.

- Blockchain for fair distribution of water resources.
- Shortage of high-quality data and complete information to learn water management models.

- High temporal variability in water-related processes such as bacteria estimation is challenge in AI modelling.

- Many studies for addressing sanitation and drinking water challenges lack enough validation, having been deployed in a single, very specific water infrastructure.

- The focus on short-term predictive models has disregarded advances in long-term reliable water predictions.

Threats

- The variety of AI techniques raises challenges to choose the most appropriate one(s), specially given the lack of staff jointly specialized in $\mathrm{AI}$ and water resources. 
Table 14 SWOT analysis of the SDG 7: Affordable and clean energy

\begin{tabular}{|c|c|}
\hline Strengths & Weaknesses \\
\hline $\begin{array}{l}\text { - Smart grids favor energy efficiency and its timely supply at an } \\
\text { optimal cost. }\end{array}$ & $\begin{array}{l}\text { - Data centers account for an estimated } 1 \% \text { to } 8 \% \text { of global energy } \\
\text { consumption. }\end{array}$ \\
\hline $\begin{array}{l}\text { - Smart meters enable the use of predictive AI to promote } \\
\text { sustainable energy consumption. }\end{array}$ & $\begin{array}{l}\text { - Additional consumption from digitisation is prone to cause } \\
\text { blackouts in developing countries. }\end{array}$ \\
\hline $\begin{array}{l}\text { - Predicting renewable energy source performance and manage- } \\
\text { ment needs, facilitates their rise. }\end{array}$ & $\begin{array}{l}\text { - Multiple barriers and no standardization difficults implementa- } \\
\text { tion of smart buildings. }\end{array}$ \\
\hline Opportunities & Threats \\
\hline
\end{tabular}

- AI coupled with IoT help growing distributed computing paradigms for decentralized grid management.

- Smarter digital energy systems are also more vulnerable to - 5G technology for remote management of massive energy infrastructures in real time.

- Autonomous and semi-autonomous robots for safer management of renewable energy plants.

- Smart, energy efficient and sustainable buildings to dramatically reduce energy consumption.

cyber-attacks.

- Smart self-sustainable buildings may constitute potential targets for cyber-crime.

- Long-term obsolescence also compromises the stability of smart buildings.
- Leveraging edge computing architecture to optimize energy consumption and foster green energy usage $[133,134]$.
- Application of predictive models, predominantly based on time series and deep learning together with blockchain technologies to enable a secure, efficient

Table 15 SWOT analysis of the SDG 12: Responsible consumption and production

Strengths $\quad$ Weaknesses

- Blockchain provides accountability and transparency in consumption policies.

- IoT drastically simplifies the picture behind production chains for their optimization.

- Machine learning on time series allow to predict and simulate production processes to reduce energy consumption and raw material overuse.

- Predictive AI to estimate consumption in buildings and facilitate resource micro-management.

- Early detection of breakdown to prevent waste.

- Big data to synergise production and consumption.

Opportunities

- Digital twins to reduce industrial waste and pollutant emissions and energy consumption.

- Production planning adapted to predicted consumption patterns to avoid unnecessary waste.

- Big data for sustainable optimize freight transport.

- Sustainable tourism driven by AI and tourist data to improve customer strategies based on demands.

- Integrate simulation models in food manufacturing to improve its sustainability.

- Land use policies based on IoT to exploit natural resources in line with biodiversity.

- Augmented reality to make society aware of the impact of goods they consume.
- Overfitting in AI models could have negative effects in energy consumption prediction in unexpected situations e.g a lockdown.

- Resource availability dependant on weather factors is difficult to predict.

- Many production processes are hard to adapt and make flexible due to high modification costs.
Threats

- Sectors such as tourism are exposed to over-exploitation in some areas of the globe. AI techniques to promote sustainability in these sectors could initially cause rejection, e.g. reducing tourist inflow in some spots.

- Sustainability and cost reduction are often two opposite goals in industrial production. The cost of integrating AI or IoT might be deemed unacceptable by firms and consumers. 
Fig. 12 Recommendations on using $\mathrm{AI}$ in the SDGs of environmental dimension: resources

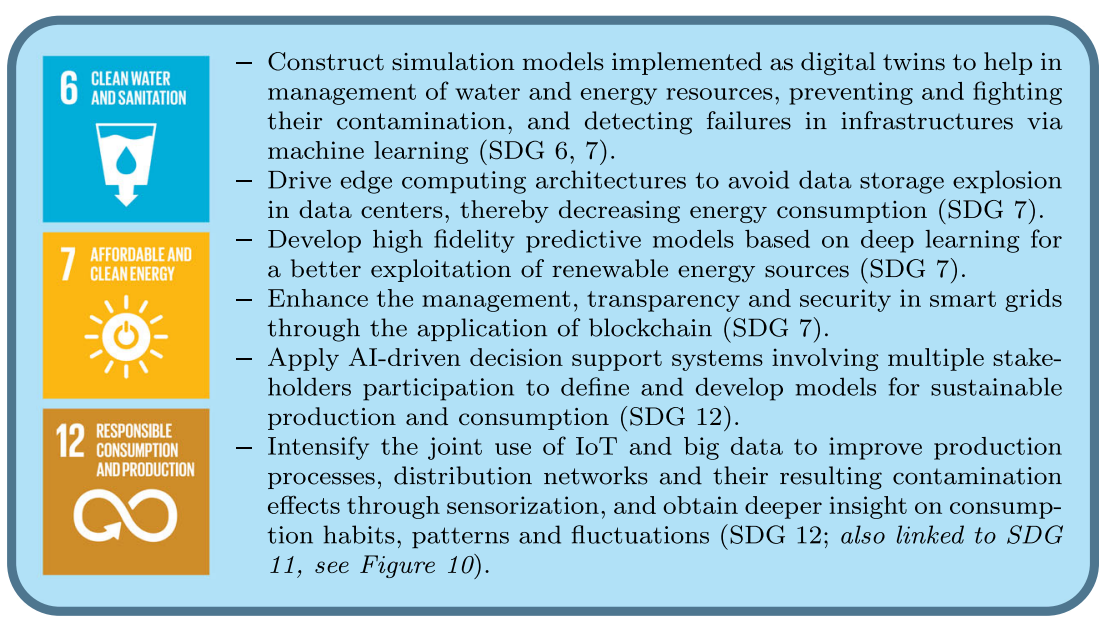

and intelligent management of electrical energy networks (e.g. smart grids), as well as enabling an efficient and predictive exploitation of renewable energy [135-137].

- Intensify the joint use of IoT and big data to improve production processes, distribution networks and consumption habits [138]. On the one hand, production chains can be massively sensorized in order to fine-tune production parameters, minimize the resulting contamination from these processes and subsequently optimize routes in distribution and supply chains. On the other hand, aspects like consumption in supermarkets based on geographical areas, demographics, etc., or movement patterns and consumption fluctuations across the time, may benefit from a sensor-driven monitoring coupled with big data analysis.

In general, the ability of AI models to fuse and process data should be embraced to develop decision-making platforms that encourage sustainable production practices
[139] and promote responsible consumption habits by citizens [140].

\subsection{Analysis for the environmental dimension: natural environment}

The last of the six analyzed SDG perspectives, natural environment, focuses on the preservation and protection of the natural environment, its quality and health, therefore it groups concerns about climate change and action (SDG 13), the health of life below water (SDG 14) and protecting life and biodiversity on land ecosystems (SDG 15). Figure 13 lists various salient recommendations to channel efforts towards sustainability in the natural environment, further to the SWOT analyses made in Tables 16, 17 and 18.

Caring for and preserving the natural environment is closely linked to an optimal use of natural resources [141, 142], where advances in AI have much to offer as described in the previous subsection. Notwithstanding, in the relation-
Fig. 13 Recommendations on using $\mathrm{AI}$ in the SDGs of environmental dimension: natural environment

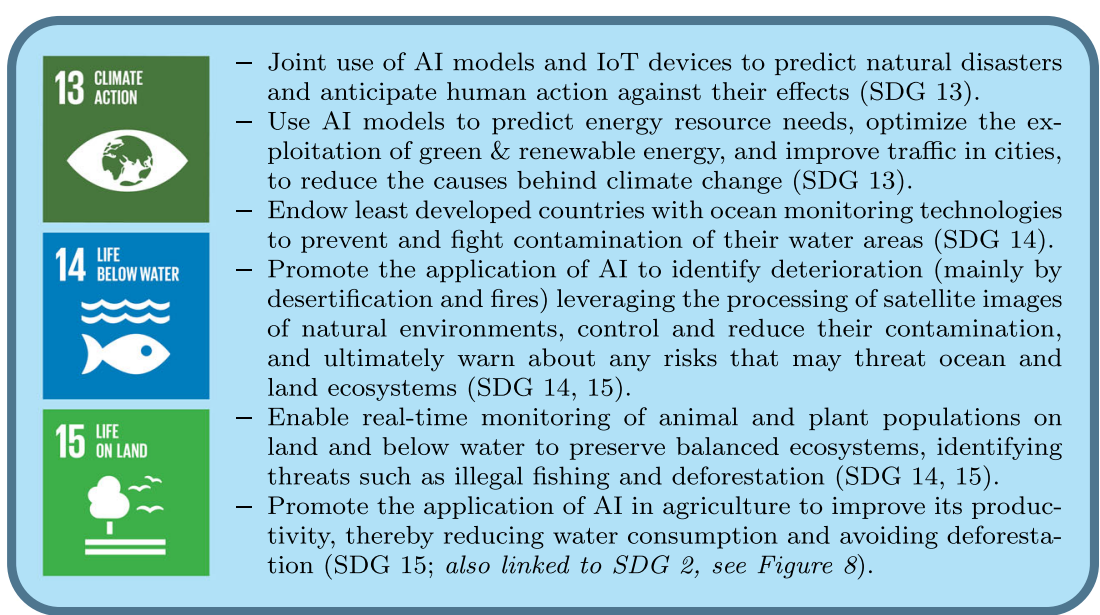


Table 16 SWOT analysis of the SDG 13: Climate action

\begin{tabular}{ll}
\hline Strengths & Weaknesses \\
\hline - Predictive AI can be applied remotely to assist disadvantaged & $\begin{array}{l}\text { - Climate prediction demands precise information in real time, not } \\
\text { affordable in certain regions. } \\
\text { countries against climate phenomena. }\end{array}$ \\
- Land and soil classification is a non-intrusive mechanism. & $\begin{array}{l}\text { - Black-box AI models are difficult to use by emergency services } \\
\text { to justify decisions against disasters. }\end{array}$ \\
- AI models help making better emergency or disaster recovery & $\begin{array}{l}\text { - Political resistance and economic cost of large-scale AI systems } \\
\text { to optimize pollutant emissions in urban areas. }\end{array}$
\end{tabular}

- AI has diverse uses in younger generations to educate them on climate change action.

Opportunities

Threats

- Early prediction of natural catastrophes enables rapid response by authorities to reduce losses.

- Rain prediction in desert areas for better understanding of desertification trends.

- AI prediction of energy needs and traffic helps reducing pollutants with major ecological impacts.

- Conversational agents and augmented reality may reinforce young people education about climate change and future.
- Climate change implies obsolescence in AI models to predict natural catastrophes upon data.

- Unexpected circumstances affecting energy consumption may hamper reliability of demand predictions.

- AI computational cost inherently requires significant energy. ship between humans and nature it is also important to note the potential damage that extreme natural events can also inflict on mankind [143, 144]. The predictive power of AI models fed by sensor data can foretell a forthcoming event [145-147], such that anticipatory action can be taken and timely decisions are made to ultimately protect human lives. Forecasting energy demand would also help acting ahead to mitigate its potential negative effects on the environment by optimizing the exploitation of cleaner energy alternatives.

The environment preservation must be also inevitably coupled with a close monitoring of its status. In this sense, the combination of AI and robotics is crucial [148]. A clear example of this is the application of deep learning models on satellite image data to: (i) identify areas under risk of desertification, (ii) preventing the deterioration of oceans, (iii) detecting prone areas to fires, and (iv) locating regions that may experience deforestation [149-152]. Likewise, the integrated use of existing AI technologies can be beneficial to:

1. Detect the deterioration of ocean ecosystems in general, and coral reefs in particular, largely as a result of plastic waste and oil dumping [153-155].

2. Tracking and monitoring animal and plant populations as well as illegal fishing and deforestation practices to preserve balanced ecosystems [156-159].

3. Detecting diseases, plagues or any type of threatening element to the survival of elements in an ecosystem [160].

Table 17 SWOT analysis of the SDG 14: Life below water

\section{Strengths}

- Diverse AI tools such as neural networks to efficiently predict water quality parameters, early oil dumping detection and ocean acidification estimation.

- Advanced tools for smart and sustainable management of fishery resources for balanced ocean ecosystems.

Opportunities

- Advanced marine ecosystem monitoring based on bio-geological and chemical data variables.

- Exploiting data from monitoring sources to obtain knowledge for predictive decision-making about sustainable exploitation of ocean resources.
Weaknesses

- Digitization of marine ecosystems incurs high economic costs.

- Fishery resource prediction and ecosystem management algorithms require massive volumes of data to make accurate estimates.

- Ocean monitoring data are difficult to obtain due to the complexity of the physical environment.

Threats

- Malicious uses of digital technologies and cyber-attacks to fishery resource prediction systems may lead to uncontrolled overexploitation.

- Dearth of intelligent monitoring and management systems in least developing countries accentuates illegal fishing, dumping and ocean pollution problems. 
Table 18 SWOT analysis of the SDG 15: Life on land

\begin{tabular}{ll}
\hline Strengths & Weaknesses \\
\hline - Early disease detection in crops to reduce herbicide use and & $\begin{array}{l}\text { - Complexity of deploying highly sophisticated drones capable of } \\
\text { environmental impact. }\end{array}$ \\
- Sensor-driven automatic fire detection for earlier, safer action and & - High-resolution image data indispensable to detect crop diseases. \\
cost reduction. & - Cost of deploying intelligent sensor networks to reduce water \\
- AI for intelligent grain/seed identification. & consumption in farmlands, not affordable to small farmers.
\end{tabular}

- Intelligent sensors for greenhouses and intensive use of farming land, reducing impact on wild areas.

- Intelligent irrigation significantly reduces water consumption.

Opportunities

- Intelligent robots and routing to automate cultivation.

- Surveillance drones to preserve land, provide non-intrusive monitoring and detect plant diseases.

- Early fire prevention and reforestation planning guided by AI to save wildlife and ecosystems.

- Farming product sale forecasting prevents over-production and waste.
Threats

- Using AI to reduce deforestation is a major challenge in least developed countries.

- Managing up-to-date warning systems on land areas implies important logistic problems.

- Major forests and rainforests -e.g. Amazon rainforest- highly sensitive to public policies and economic status of countries.
4. Minimizing water consumption in farming activities and increasing their productivity [48], so as to prevent avoidable deforestation in wild areas.

\section{Five key elements and priorities which should be globally understood: a decade roadmap}

The economic and societal impact of intelligent and digital technologies increases on a continuous basis, thus making it imperative to reflect on such impact along the recently started decade, from an Agenda 2030 viewpoint. In order to stimulate this much needed reflection -and after having analyzed the SDGs, discussed opportunities and proposed recommended actions under each of the six perspectives of human needs considered- this section provides a general discussion about broader application of AI technologies to attain the 17 goals set by the Agenda 2030 over the course of the coming years.

The discussion is intended to provide guidelines applicable to all the SDGs for unveiling the catalysing potential of $\mathrm{AI}$ in the achievement of such goals along the decade. Therefore, it revolves around five key elements or priorities which should be understood as a pre-requisite for the recommended lines of action provided in this study to have optimal results and impact (see Fig. 14):

A) AI fueled by universally accessible and reliable data. Data are the common element or "fuel" on which most of the reviewed AI technologies are presently founded, be it because (i) data are the essential component for AI systems to be able to perform the task they are designed for, also (ii) because they are increasingly acquired, produced, transformed and transmitted in virtually any setting. In general terms, a high availability of large volumes of data greatly facilitates extracting useful knowledge about the real-world problem to address. Consequently, the application of AI to achieve the SDGs necessitates unified, accessible, open and highquality data more than ever before. These data must also abide to inalienable human rights in order to design and develop models that can solve the myriad challenges underlying the SDGs.

B) Strengthen science-industry-government dialogue and technology transfer. The literature analysis undertaken in this study has revealed that many of the advances made on AI applications has not been comprehensively applied to some of the targets underlying the SDGs yet. This is arguably due to several factors, such as the weak or insufficiently solid relationship and cooperation between research, industry and governments, as well as the unavailability of unified data that may help tackling many of the existing challenges. Therefore, it is imperative to strengthen the links between science, industry and institutions, reinforcing their dialogue, opening up new pathways and widening existing ones to have high-quality data available, and further pursuing a much needed technology transfer to facilitate their immediate application in line with SDG targets. 


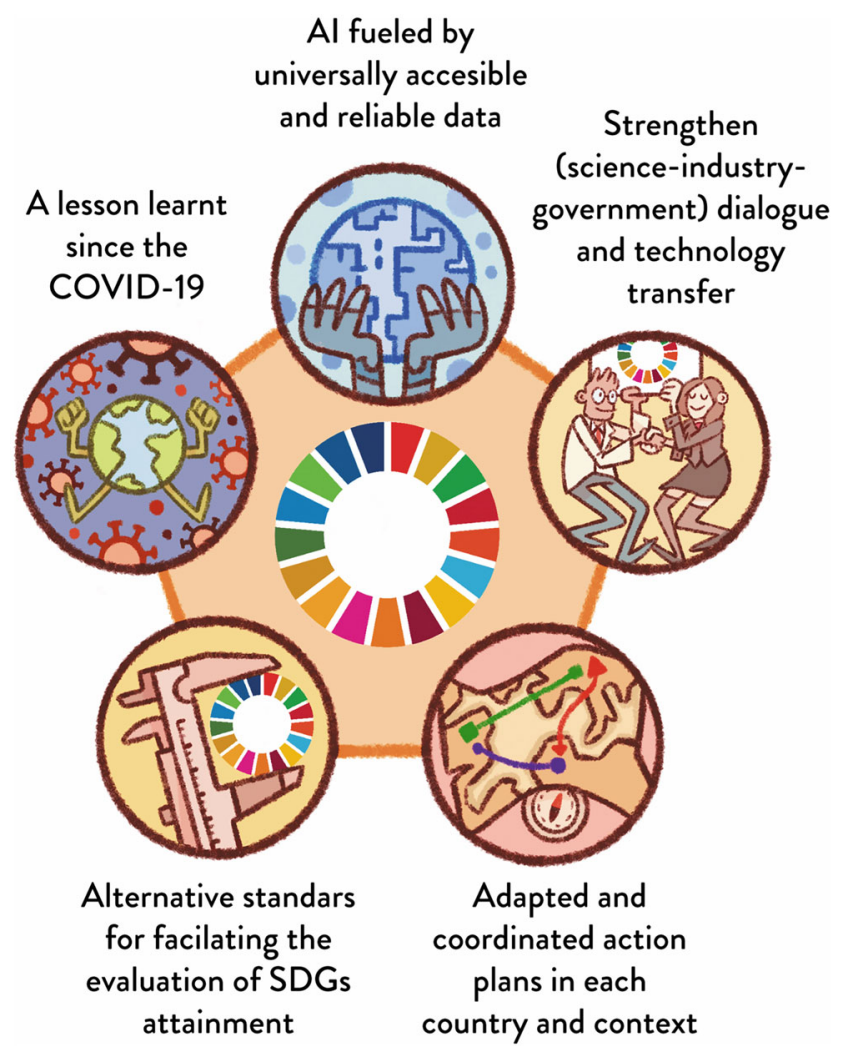

Fig. 14 A "decade roadmap" of five key priorities to advance the SDGs guided by AI technologies

C) Adapted and coordinated action plans in each country and context. The SDGs propose targets to be achieved globally, yet not all countries and regions across the globe are currently at the same position in this race towards achieving such targets. It is therefore clear that the present and future application of AI and digital technologies must be carefully adapted to the situation and characteristics of each country, coordinated with other actions being considered due to the synergistic relationships between SDGs, and prioritising the most urgently needed objectives in a given nation. For instance, a line of action with immediate effectiveness and positive impact in highly developed countries with prevalence of highly qualified working population -such as the automation of production and industrial processes- may require special attention and care in a less developed country or region where the majority of people have a less advantaged working or socio-economic profile. A well-oriented, tailored approach to put these lines of action forward, and an appropriate coordination with other recommended actions -e.g. decent education, training and work to prevent negative effects of automation- may mitigate risks of aggravating digital, salary and employment breaches in such regions.

D) Alternative standards for facilitating the evaluation of SDGs attainment. Every goal requires evaluation standards and indicators to realistically measure their level of attainment. The 17 SDGs have a well-defined repertoire of associated indicators, yet some of them are difficult to quantify, thereby hampering their use as an evaluation metric. Because of this, we argue that is is necessary to promote the definition of alternative and more flexible standards for their evaluation. Digital technologies are advancing at an unprecedented pace, which also stresses the importance of seeking alternative ways to assess the degree of achievement of every SDG. Such approaches should adapt to the accelerated rhythm of progress witnessed in these technologies, as well as the emergence of new digital paradigms.

E) A final lesson learnt since the COVID-19 pandemic. Last but not least, a critically important glance must be put on the current global scenario originated by the COVID-19 pandemic, which has undoubtedly had a profound impact in all the SDG dimensions, far beyond a strictly health-related viewpoint. Both the overall social and economic welfare of human beings and the environment are being severely affected by the current exceptional situation. More worryingly, this is even revealing and highlighting many emerging threats to sustainability, most of which were not apparent until now, as well as aggravating problems that already were being tackled. On a critical note, even the assumed robustness of many of the implementations and advances made globally in the last years under the scope of the Agenda 2030 are being seriously questioned nowadays, because of the dramatic and very rapid setbacks caused by the pandemic.

Beyond the undeniably negative consequences of the COVID-19 pandemic, this situation should be ultimately raised as an opportunity for (rather mandatory) reflection and reformulation of the approaches under which each and every SDG in the UN agenda are being currently addressed. This can be done by analyzing and identifying pathways of proven effectiveness and robustness against situations like the aforesaid pandemic, but also rethinking those other pathways in which areas for improvement or strengthening have been unveiled. Based on the recommendations formulated along this study, the above proposed reflections should always bear in mind the potential of AI and digital technologies (both present and future ones) to pave the way towards the long-desired targets defined by the 17 SDGs. 


\section{Concluding remarks}

This paper presented a snapshot, general view and reflection on the role and impact of AI and its surrounding technologies in attaining the Agenda 2030 for sustainable development, namely its 17 Sustainable Development Goals (SDGs). Based on an in-depth analysis of relevant literature and a series of SWOT analyses to portrait the nexus between AI technologies and each of the SDGs, the study provided a position analysis of the challenges and opportunities for progress led by these technologies, under different dimensions of perspectives of human needs underlying the SDGs. Likewise, a final discussion of key guidelines or priorities to adopt for ensuring a positive progress towards the aforesaid goals by 2030 , has been presented.

The main insight of the analysis presented is the contribution of AI-based technologies for encouraging the procurement of the SDGs. Nonetheless, we also bring up that the intensive use of those technologies might undermine their positive contributions to the SDGs. In particular, the last advances on AI are addressed by increasingly large and computationally intensive deep learning models [161], which are associated to considerable computational costs. For instance, the carbon footprint and the environmental costs of those intensive AI models in natural language processing tasks are showed in [162]. This evidence has boosted a nascent research line in the AI field known as Green AI [161] that proposes to consider the efficiency of AI algorithms for assessing them alongside accuracy and other related measures. In this line, a measure to quantify the carbon footprint of an algorithm is proposed in [163]. ${ }^{8}$ Accordingly, we remark that the AI field must seriously consider the development of efficient AI algorithms and minimize the discrepancy between accuracy and environmental costs in order to really contribute to the attainment of the SGDs [164].

To conclude, we provide a triple closing remark to put a final glance on the future of $\mathrm{AI}$ (and emerging technologies) as a facilitator for the SDGs.

I. Firstly, we stress that in the process of leveraging AIbased technologies for the sake of sustainability, it is always crucial to bear in mind the symbiotic relationship that exists between AI and various digital technologies to optimally interact, reason, perceive, learn from stimuli/data and act in a given environment, as well as ensuring communication and effective cooperation among AI systems. Some of these digital technologies are giving rise to paradigms that have an unquestionably central role to drive SDGs in

\footnotetext{
${ }^{8}$ You can measure the carbon footprint of your algorithm at http:// www.green-algorithms.org/.
}

nowadays contexts of digital transformation, e.g. smart cities/territories and digital twins.

II. Secondly, we underline the importance of the currently undergoing digital transformation in the development of the SDGs, particularly at societal level. Both AI and its associated digital technologies are fundamental instruments to advance along the road to be travelled over the course of the newly started decade.

III. Thirdly, we emphasize the enormous and everincreasing importance of data in virtually any AI-based solution to pursue the SDGs. Nowadays AI systems are fueled by big data, therefore we need to fully embrace the value that high-quality, open and large-scale data infrastructures can bring to AI solutions for pursuing the whole spectrum of SDGs across all their dimensions globally. The potential benefits of AI approaches guided by big data would amply compensate for their high computational cost, which often hinders their adoption by project managers, practitioners and organizations.

We must continue this journey with a high ethical responsibility towards our world, towards people inhabiting it and towards future generations. Following the path drawn by United Nations' Agenda 2030 is a great opportunity and a great challenge in equal proportions.

Acknowledgment This work was supported by the contract OTRI4408 between the University of Granada and the Royal Academy of Engineering of Spain financed by Ferrovial S.A. Eugenio Martínez Cámara was supported by the Spanish Government fellowship programme Juan de la Cierva Incorporación (IJC2018-036092-I).

\section{References}

1. Berman SJ, Bell R et al (2011) Digital transformation: Creating new business models where digital meets physical. IBM Institute for Business Value, pp 1-17

2. Bublitz FM, Oetomo A, Sahu KS, Kuang A, Fadrique LX, Velmovitsky PE, Nobrega RM, Morita PP (2019) Disruptive technologies for environment and health research: An overview of artificial intelligence, blockchain, and internet of things. International Journal of Environmental Research and Public Health 16:3847

3. Makridakis S (2017) The forthcoming artificial intelligence (ai) revolution: Its impact on society and firms. Futures 90:46-60

4. Forum WE (2018) Driving the sustainability of production systems with fourth industrial revolution innovation. In: World economic forum. Geneva, Switzerland

5. Liu G, Yang J, Hao Y, Zhang Y (2018) Big data-informed energy efficiency assessment of china industry sectors based on k-means clustering. J Clean Prod 183:304-314

6. Müller JM, Buliga O, Voigt KI (2018) Fortune favors the prepared: How SMEs approach business model innovations in industry 4.0. Technol Forecast Soc Chang 132:2-17

7. Dunis C, Middleton P, Karathanasopolous A, Theofilatos K (2016) Artificial intelligence in financial markets. Springer, Berlin 
8. Lytras MD, Chui KT (2019) The recent development of artificial intelligence for smart and sustainable energy systems and applications. Energies 12(16):3108

9. Mao C, Tao X, Yang H, Chen R, Liu G (2018) Real-time carbon emissions monitoring tool for prefabricated construction: An iot-based system framework. In: ICCREM 2018: Sustainable construction and prefabrication, pp 121-127. American Society of Civil Engineers Reston, VA

10. PwC (2017) Sizing the price: what's the real value of AI for your business and how can you capitalise? Global Artificial Intelligence Study. Accessed Dec 2020: http://www.pwc.com/AI

11. Goralski MA, Tan TK (2020) Artificial intelligence and sustainable development. The International Journal of Management Education 18(1): 100330

12. Truby $\mathbf{J}$ (2020) Governing artificial intelligence to benefit the un sustainable development goals. Sustain Dev 28(4):946-959

13. Vinuesa R, Azizpour H, Leite I, Balaam M, Dignum V, Domisch S, Felländer A, Langhans SD, Tegmark M, Nerini FF (2020) The role of artificial intelligence in achieving the sustainable development goals. Nat Commun 11(1):1-10

14. Wu J, Guo S, Huang H, Liu W, Xiang Y (2018) Information and communications technologies for sustainable development goals: State-of-the-art, needs and perspectives. IEEE Communications Surveys Tutorials 20(3):2389-2406

15. Nguyen QK (2016) Blockchain - a financial technology for future sustainable development. In: 2016 3rd International conference on green technology and sustainable development (GTSD), pp 51-54

16. Zwitter A, Herman J (2018) Blockchain for sustainable development goals. University of Groningen, Report 2018 72018 Ed.

17. United Nations (2015) Transforming our world: the 2030 Agenda for Sustainable Development. UN General Assembly, New York: United Nations

18. McCarthy J, Minsky ML, Rochester N, Shannon CE (1955) A proposal for the Dartmouth summer research project on artificial intelligence

19. Tegmark M (2017) Life 3.0: Being human in the age of artificial intelligence. Alfred A. Knopf

20. European Commission. High-Level Expert Group on Artificial Intelligence (2019) A definition of artificial intelligence: main capabilities and scientific disciplines. Available at https:// ec.europa.eu/digital-single-market/en/news/definition-artificialintelligence-main-capabilities-and-scientific-disciplines

21. Turing AM (1950) Mind. Computing machinery and intelligence 59(236):433-460

22. Russell S, Norvig P (2009) Artificial intelligence: A modern approach. Prentice Hall Press, USA

23. Bishop CM (2006) Pattern recognition and machine learning (information science and statistics). Springer-Verlag, Berlin, Heidelberg

24. Maurer M, Gerdes J, Lenz B, Winner H (2016) Autonomous driving: Technical, legal and social aspects. Springer, Berlin

25. Arrieta AB, Díaz-Rodríguez N, Ser JD, Bennetot A, Tabik S, Barbado A, Garcia S, Gil-Lopez S, Molina D, Benjamins R, Chatila R, Herrera F (2020) Explainable artificial intelligence (XAI): Concepts, taxonomies, opportunities and challenges toward responsible AI. Information Fusion 58:82-115

26. European Commission. High-Level Expert Group on Artificial Intelligence (2019) Ethics guidelines for trustworthy AI

27. Tan L, Wang N (2010) Future internet: The internet of things. 2010 3rd International Conference on Advanced Computer Theory and Engineering(ICACTE) 5:V5-376-V5-380

28. Boer CR, Jovane F, Sacco M, Imperio E (1997) Virtual reality as a tool for sustainable production in the ManuFuturing model. In: Venuvinod PK, Djordjevich A (eds) CIRP International
Symposium on Advanced Design and Manufacture in the Global Manufacturing Era, Vol 2, pp 518-524

29. Gebler M, Uiterkamp AJM, Visser C (2014) A global sustainability perspective on $3 \mathrm{~d}$ printing technologies. Energy Policy 74:158-167

30. Hui H, Ding Y, Shi Q, Li F, Song Y, Yan J (2020) 5g networkbased internet of things for demand response in smart grid: A survey on application potential. Appl Energy 257:113972

31. Barocas S, Selbst A (2016) Big data's disparate impact. California Law Review 104:671

32. Kshetri N (2014) The emerging role of big data in key development issues: Opportunities, challenges, and concerns. Big Data \& Society, June-December 2014, pp 1-20

33. Whyte J, Coca D, Fitzgerald J, Mayfield M, Pierce K, Shah N, Chen L, Gamble C, Genes C, Babovic F, et al. (2019) Analysing systems interdependencies using a digital twin. Centre for Digital Built Brain (CDBB) Report

34. Anastasi G, Antonelli M, Bechini A, Brienza S, De Andrea E, De Guglielmo D, Ducange P, Lazzerini B, Marcelloni F, Segatori A (2013) Urban and social sensing for sustainable mobility in smart cities. In: Proc. Sustainable Internet and ICT for Sustainability (SustainIT), pp 1-4

35. Venezia E, Vergura S (2015) Transport issues and sustainable mobility in smart cities. In: Proc. International Conference on Clean Electrical Power (ICCEP), pp 360-365

36. Zhang X, Ghorbani AA (2020) An overview of online fake news: Characterization, detection, and discussion. Information Processing \& Management 57(2):102025

37. Tong L, Hong T, Jing-hua Z (2015) Research on the big databased government decision and public information service model of food safety and nutrition industry. Journal of Food Safety and Quality 6:366-371

38. Wang W, Siau K (2018) Artificial intelligence: a study on governance, policies and regulations. In: MWAIS 2018 proceedings, vol. 40

39. Sarangi S (2020) Blockchain, AI, IoT: How india can help farmers by leveraging these technologies. Financial Express, May 2020. https://www.financialexpress.com/opinion/blockchain-aiiot-how-india-can-help-farmers-by-leveraging-these-technologies/ 1970409/

40. Lin J, Shen Z, Zhang A, Chai Y (2018) Blockchain and IoT based food traceability for smart agriculture. In: Proceedings of the 3rd international conference on crowd science and engineering, pp ICCSE'18

41. Reichental A (2019) How blockchain can address food waste and hunger. Forbes Report, Forbes Technology Council. https://www.forbes.com/sites/forbestechcouncil/2019/12/26/ how-blockchain-can-address-food-waste-and-hunger/

42. Parfitt J, Barthel M, Macnaughton S (2010) Food waste within food supply chains: quantification and potential for change to 2050. Philosophical Transactions of the Royal Society B: Biological Sciences 365(1554):3065-3081

43. Shafiee-Jood M, Cai X (2016) Reducing food loss and waste to enhance food security and environmental sustainability. Environmental science \& technology 50 16:8432-43

44. Blumenstock JE, Cadamuro G, On R (2015) Predicting poverty and wealth from mobile phone metadata. Science 350:10731076

45. Jean N, Burke M, Xie M, Davis WM, Lobell DB, Ermon S (2016) Combining satellite imagery and machine learning to predict poverty. Science 353(6301):790-794

46. Njuguna C, McSharry PE (2017) Constructing spatiotemporal poverty indices from big data. J Bus Res 70:318-327

47. Xie M, Jean N, Burke M, Lobell D, Ermon S (2016) Transfer learning from deep features for remote sensing and poverty mapping. In: Proceedings of the thirtieth AAAI conference 
on artificial intelligence, AAAI'16, pp 3929-3935. AAAI Press

48. Wolfert S, Ge L, Verdouw C, Bogaardt M-J (2017) Big data in smart farming - a review. Agric Syst 153:69-80

49. Afzal M, Islam SMR, Hussain M, Lee S (2020) Precision medicine informatics: Principles, prospects, and challenges. IEEE Access 8:13593-13612

50. Ahmed Z, Mohamed K, Zeeshan S, Dong X (2020) Artificial intelligence with multi-functional machine learning platform development for better healthcare and precision medicine. Database: The Journal of Biological Databases and Curation 2020: baaa010

51. Davenport T, Kalakota R (2019) The potential for artificial intelligence in healthcare. Future Healthcare Journal 6:94-98

52. Doshi R, Falzon D, Thomas BV, Temesgen Z, Sadasivan L, Migliori G, Raviglione M (2017) Tuberculosis control, and the where and why of artificial intelligence. ERJ Open Research $3(2): 1-5$

53. Malak JS, Zeraati H, Nayeri FS, Safdari R, Shahraki AD (2018) Neonatal intensive care decision support systems using artificial intelligence techniques: a systematic review. Artif Intell Rev, pp 1-20

54. Hu H, Moturu P, Dharan K, Geller J, Iorio S, Phan H, Vo H, Chun S (2018) Deep learning model for classifying drug abuse risk behavior in tweets. In: 2018 IEEE International conference on healthcare informatics (ICHI), pp 386-387

55. Kagashe I, Yan Z, Suheryani I (2017) Enhancing seasonal influenza surveillance: Topic analysis of widely used medicinal drugs using twitter data. Journal of Medical Internet Research 19(9):e315

56. Rahmattalabi A, Barman-Adhikari A, Vayanos P, Tambe M, Rice E, Baker R (2018) Influence maximization for social network based substance abuse prevention. In: AAAI

57. Nadarzynski T, Bayley J, Llewellyn C, Kidsley S, Graham CA (2020) Acceptability of artificial intelligence (ai)-enabled chatbots, video consultations and live webchats as online platforms for sexual health advice. BMJ Sexual \& Reproductive Health 46(3):210-217

58. Elsweiler D, Harvey M, Ludwig B, Said A (2015) Bringing the "healthy" into food recommenders. In: Proceedings of the 2nd international workshop on decision making and recommender systems, pp 33-36

59. Smyth B (2019) Recommender systems: A healthy obsession. In: The thirty-third AAAI conference on artificial intelligence, AAAI, pp 9790-9794. AAAI Press

60. Trattner C, Elsweiler D (2019) An evaluation of recommendation algorithms for online recipe portals. In: Proceedings of the 4th International Workshop on Health Recommender Systems co-located with the 13th ACM Conference on Recommender Systems 2019 (RecSys 2019), pp 24-28

61. Alcaraz-Herrera H, Palomares I (2019) Evolutionary approach for 'healthy bundle' wellbeing recommendations. In: Proceedings of the 4th International Workshop on Health Recommender Systems co-located with the 13th ACM Conference on Recommender Systems 2019 (RecSys 2019), pp 18-23

62. Hors-Fraile S, de Vries H, Malwade S, Luna-Perejon F, Amaya C, Civit A, Schneider F, Bamidis P, Syed-Abdul S, Li Y (2019) Opening the black box: Explaining the process of basing a health recommender system on the i-change behavioral change model. IEEE Access 7:176525-176540

63. Ong E, Wong MU, Huffman A, He Y (2020) Covid-19 coronavirus vaccine design using reverse vaccinology and machine learning. Front Immunol 11:1581

64. Tabik S, Gómez-Ríos A, Martin-Rodriguez JL, Sevillano-Garc'ia I, Rey-Area M, Charte D, Guirado E, Suarez JL, Luengo J,
Valero-González MA, Garcia-Villanova P, Olmedo-S'anchez E, Herrera F (2020) COVIDGR dataset and COVID-SDNet methodology for predicting covid-19 based on chest x-ray images. arXiv:2006.01409

65. Kummitha R (2020) Smart technologies for fighting pandemics: The techno- and human- driven approaches in controlling the virus transmission. Gov Inf Q 37:101481-101481

66. Meskó B, Hetényi G, Győrffy Z (2018) Will artificial intelligence solve the human resource crisis in healthcare? BMC Health Serv Res 18(1):1-4

67. Frize M, Yang L, Walker RC, O’Connor AM (2005) Conceptual framework of knowledge management for ethical decisionmaking support in neonatal intensive care. IEEE Trans Inf Technol Biomed 9(2):205-215

68. Arntz M, Gregory T, Zierahn U (2016) The risk of automation for jobs in OECD countries. OECD Social, Employment and Migration Working Papers 189:1-34

69. Chiacchio F, Petropoulos G, Pichler D (2018) The impact of industrial robots on EU employment and wages: A local labour market approach. Bruegel Working Paper 2018/02, Bruegel

70. Choi J, Lee MG, Seok Oh H, Bae SG, An JH, Yun DJ, Park HS (2019) Multi-objective green design model to mitigate environmental impact of construction of mega columns for super-tall buildings. Science of The Total Environment 674:580 591

71. Frey CB, Osborne MA (2017) The future of employment: How susceptible are jobs to computerisation? Technological forecasting and social change 114:254-280

72. Petropoulos G (2018) The impact of artificial intelligence on employment. Praise for Work in the Digital Age, pp 119-132

73. Leng J, Ruan G, Jiang P, Xu K, Liu Q, Zhou X, Liu C (2020) Blockchain-empowered sustainable manufacturing and product lifecycle management in industry 4.0: A survey. Renew Sust Energ Rev 132:110112

74. Liu L, Han M, Zhou Y, Parizi RM, Korayem M (2020) Blockchain-based certification for education, employment, and skill with incentive mechanism. In: Blockchain cybersecurity, trust and privacy, pp 269-290. Springer

75. Woolf BP, Lane HC, Chaudhri VK, Kolodner JL (2013) AI grand challenges for education. AI magazine 34(4):66

76. Acemoglu D, Restrepo P (2020) The wrong kind of AI artificial intelligence and the future of labour demand. Cambridge Journal of Regions, Economy and Society 13(1):25-35

77. Gonçalves-Machado C, Winroth MP, Ribeiro da Silva EHD (2020) Sustainable manufacturing in industry 4.0: an emerging research agenda. Int J Prod Res 58(5):1462-1484

78. Rocha CF, Mamédio DF, Quandt CO (2019) Startups and the innovation ecosystem in industry 4.0. Technology Analysis \& Strategic Management 31(12):1474-1487

79. Lu W (2019) Big data analytics to identify illegal construction waste dumping: A Hong Kong study. Resour Conserv Recycl 141:264-272

80. Olivera AC, García-Nieto JM, Alba E (2015) Reducing vehicle emissions and fuel consumption in the city by using particle swarm optimization. Appl Intell 42(3):389-405

81. Sadatsafavi H, Kim A, Anderson SD, Bishop P (2019) Scenario planning application in US highway transportation industry. J Infrastruct Syst 25(2):05019002

82. Singh A, Kumar D, Hötzel J (2018) IoT based information and communication system for enhancing underground mines safety and productivity: genesis, taxonomy and open issues. Ad Hoc Netw 78:115-129

83. Plekhanov D, Keenan M, Galindo-Rueda F, Ker D (2018) OECD science, technology and innovation outlook 2018. OECD, pp 261-278 
84. Marconcini M, Metz A, Zeidler J, Esch T (2015) Urban monitoring in support of sustainable cities. In: Proc. Joint Urban Remote Sensing Event (JURSE), pp 1-4

85. Vasileios S, Konstantinos L, Nikos N, Nikolaos M, Paraskevi G, A. K (2020) An investigation on the feasibility of near-zero and positive energy communities in the greek context. Smart Cities 3:362-384

86. Villagra A, Alba E, Luque G (2020) A better understanding on traffic light scheduling: New cellular gas and new indepth analysis of solutions. Journal of Computational Science 41:101085. https://doi.org/10.1016/j.jocs.2020.101085

87. Vilajosana I, Llosa J, Martinez B, Domingo-Prieto M, Angles A, Vilajosana X (2013) Bootstrapping smart cities through a selfsustainable model based on big data flows. IEEE Commun Mag 51(6):128-134

88. Lu R, Rausch C, Bolpagni M, Brilakis I, Haas CT (2020) Geometric accuracy of digital twins for structural health monitoring. In: Bridge engineering. IntechOpen

89. Saracco R (2018) Digital twins take the train. IEEE Future Directions

90. Dia H (2001) An object-oriented neural network approach to short-term traffic forecasting. Eur J Oper Res 131(2):253261

91. Barlacchi G, De Nadai M, Larcher R, Casella A, Chitic C, Torrisi G, Antonelli F, Vespignani A, Pentland A, Lepri B (2015) A multi-source dataset of urban life in the city of Milan and the province of Trentino. Scientific data 2(1):1-15

92. Al-Naji A, Perera AG, Mohammed SL, Chahl J (2019) Life signs detector using a drone in disaster zones. Remote Sens 11(20):2441

93. Bellosio B, Giaccone L, Guerrisi A, Lazzeroni P, Martino M, Tartaglia M (2011) Energy networks in sustainable cities: Towards a full integration of renewable systems in urban area. In: Proc. 37th annual conference on IEEE industrial electronics society (IECON), pp 3146-3151

94. Castelli M, Sormani R, Trujillo L, Popovič A (2017) Predicting per capita violent crimes in urban areas: an artificial intelligence approach. Journal of Ambient Intelligence and Humanized Computing 8(1):29-36

95. Joshi D, Khalegaonkar M, Lohikpure M, Mann P, Deshmukh RA (2017) Sentimental analysis on e-governance. International Journal of Innovative Research in Science and Engineering, vol $3(5)$

96. Chizoba PN, Abomeh OS, Chika M, Mbanjide M (2019) Impact of participatory decision making on organisational goal attainment. International journal of business and economics 6:115

97. Nambisan S, Nambisan P (2013) Engaging citizens in cocreation in public services: Lessons learned and best practices. IBM Center for the Business of Government - Collaboration Across Boundaries Series

98. Adam I, Fazekas M (2018) Are emerging technologies helping win the fight against corruption in developing countries? Pathways for Prosperity Commission. Background Paper Series (21)

99. Beasley MS, Carcello JV, Hermanson DR, Lapides PD (2000) Fraudulent financial reporting: Consideration of industry traits and corporate governance mechanisms. Accounting horizons 14(4):441-454

100. Lima MSM, Delen D (2020) Predicting and explaining corruption across countries: A Machine Learning approach. Gov Inf Q 37(1):101407

101. Greene D, Hoffmann A, Stark L (2019) Better, nicer, clearer, fairer: A critical assessment of the movement for ethical artificial intelligence and machine learning. In: HICSS
102. Anderson K, Ryan B, Sonntag W, Kavvada A, Friedl L (2017) Earth observation in service of the 2030 agenda for sustainable development. Geo-spatial Information Science 20:77-96

103. Smith MRW, Neupane S (2018) Artificial intelligence and human development : toward a research agenda. In: White paper, international development research centre

104. The Blue DOT: issue 9 (2018) Artificial intelligence and the future of education. UNESCO MGIEP. Accessed July 2020: https:// www.schooleducationgateway.eu/en/pub/resources/publications/theblue-dot-issue-9-ai-in-edu.htm

105. World Education Forum (2016) Incheon declaration and framework for action. education 2030: Towards inclusive and equitable quality education and lifelong learning for all. Accessed July 2020: http://uis.unesco.org/sites/default/files/documents/education2030-incheon-framework-for-action-implementation-of-sdg4-20162016-en_2.pdf

106. Pan Z, Cheok AD, Yang H, Zhu J, Shi J (2006) Virtual reality and mixed reality for virtual learning environments. Computers \& Graphics 30(1):20-28. https://doi.org/10.1016/j.cag.2005.10. 004. http://www.sciencedirect.com/science/article/pii/S0097849 305002025

107. Zhou J, Riekki J, Hämäläinen M, Mattila P, Yu X, Liu X, Zhang W (2018) China-finland educloud platform towards innovative education. In: Satoh S (ed) Image and video technology, pp 172185. Springer International Publishing, Cham

108. Palomares I, Porcel C, Pizzato L, Guy I, Herrera-Viedma E (2021) Reciprocal recommender systems: Analysis of state-ofart literature, challenges and opportunities on social recommendation. Information Fusion In Press. https://doi.org/10.1016/ j.inffus.2020.12.001

109. Ma W, Adesope OO, Nesbit JC, Liu Q (2014) Intelligent tutoring systems and learning outcomes: A meta-analysis. J Educ Psychol 106:901-918

110. Webster R (2016) Declarative knowledge acquisition in immersive virtual learning environments. Interact Learn Environ 24(6):1319-1333

111. Zhuhadar L, Marklin S, Thrasher E, Lytras MD (2016) Is there a gender difference in interacting with intelligent tutoring system? can bayesian knowledge tracing and learning curve analysis models answer this question? Comput Hum Behav 61:198-204

112. Sobir R (2020) Micro-, small and medium-sized enterprises (MSMEs) and their role in achieving the sustainable development goals. Department of Economic and Social Affairs. Available at https://sustainabledevelopment.un.org/content/documents/ 26073MSMEs_and_SDGs.pdf

113. Hammond A, Young D (2018) Can blockchain disrupt gender inequality?. Available at https://blogs.worldbank.org/psd/ can-blockchain-disrupt-gender-inequality

114. Noriega M (2020) The application of artificial intelligence in police interrogations: An analysis addressing the proposed effect AI has on racial and gender bias, cooperation, and false confessions. Futures 117:102510

115. Njoto S (2020) Gendered bots?: Bias in the use of artificial intelligence in recruitment. The University of Melbourne. Accessed September 2020: https://arts.unimelb.edu.au/__data/ assets/pdf_file/0008/3440438/Sheilla-Njoto-Gendered-Bots.pdf

116. Raub M (2018) Bots, bias and big data: Artificial intelligence, algorithmic bias and disparate impact liability in hiring practices. In: Arkansas law review vol 71(2), p 7

117. Robertson D, Ayazi M (2019) How women are using technology to advance gender equality and peace. Available at https://www. usip.org/publications/2019/07/how-women-are-using-technologyadvance-gender-equality-and-peace

118. Chen H, Mckeever S, Delany SJ (2017) Harnessing the power of text mining for the detection of abusive content in social media. 
In: Advances in Computational Intelligence Systems, pp 187205. Springer

119. Francescato D (2018) Globalization, artificial intelligence, social networks and political polarization: New challenges for community psychologists. In: Community psychology in global perspective, vol 4, pp 20-41

120. Molina-Gil J, Concepción-Sánchez JA, Caballero-Gil P (2019) Harassment detection using machine learning and fuzzy logic techniques. In: Multidisciplinary digital publishing institute proceedings, vol 31, p 27

121. Frank M, Roehrig P, Pring B (2017) What to do when machines do everything: How to get ahead in a world of ai, algorithms, bots, and big data. John Wiley \& Sons, Hoboken

122. Shu K, Sliva A, Wang S, Tang J, Liu H (2017) Fake news detection on social media: A data mining perspective. arXiv:1708.01967

123. Wagner TL, Blewer A (2019) "The Word Real Is No Longer Real": Deepfakes, gender, and the challenges of AI-altered video. Open Information Science 3(1):32-46

124. Palomares I (2018) Large group decision making: creating decision support approaches at scale. In: SpringerBriefs in computer science

125. Reisman D, Whittaker M, Crawford K (2018) Algorithms are making government decisions. the public needs to have a say. Contribution to the ACLU series on exploring the impacts of artificial intelligence on civil liberties (2018). Accessed September 2020, https://www.aclu.org/issues/privacy-technology/surveillancetechnologies/algorithms-are-making-government-decisions

126. Sourdin T (2018) Judge v. robot: Artificial intelligence and judicial decision-making. UNSW Law Journal 41:1114

127. Comas J, Poch M (2010) Decision support systems for integrated water resources management under water scarcity. In: Water scarcity in the mediterranean: Perspectives under global change, Handbook of Environmental Chemistry Series, vol 8, pp 129146

128. Mirauda D, Erra U, Agatiello R, Cerverizzo M (2017) Applications of Mobile Augmented Reality to Water Resources Management. Water 9(9):699

129. Zendehboudi A, Baseer MA, Saidur R (2018) Application of support vector machine models for forecasting solar and wind energy resources: A review. J Clean Prod 199:272-285

130. Tinelli S, Juran I (2019) Artificial intelligence-based monitoring system of water quality parameters for early detection of non-specific bio-contamination in water distribution systems. Water Science and Technology-Water Supply 19(6):17851792

131. Zhang G, Yan Y, Tian Y, Liu Y, Li Y, Zhou Q, Zhou R, Li K-C (2019) Water contamination monitoring system based on big data: a case study. International Journal of Computational Science and Engineering 19(4, SI):494-505

132. Bohorquez J, Alexander B, Simpson AR, Lambert MF (2020) Leak detection and topology identification in pipelines using fluid transients and artificial neural networks. Journal of Water Resources Planning and Management 146(6):04020040

133. Karam A, Zaher K, Mahmoud AS (2020) Comparative studies of using nano zerovalent iron, activated carbon, and green synthesized nano zerovalent iron for textile wastewater color removal using artificial intelligence, regression analysis, adsorption isotherm, and kinetic studies. Air Soil and Water Research 13:1-19

134. Ziwei L, Borong L, Shanwen Z, Yanchen L, Zhe W, Jian D (2020) A review of operational energy consumption calculation method for urban buildings. Building Simulation 13:739-751

135. Kim S-K, Huh J-H (2020) Blockchain of carbon trading for un sustainable development goals. Sustainability 12(10):4021
136. Kumari A, Gupta R, Tanwar S, Kumar N (2020) Blockchain and AI amalgamation for energy cloud management: Challenges, solutions, and future directions. Journal of Parallel and Distributed Computing 143:148-166

137. Li Y (2019) Prediction of energy consumption: Variable regression or time series? A case in China. Energy Science \& Engineering 7(6):2510-2518

138. Kuo T-C, Smith S (2018) A systematic review of technologies involving eco-innovation for enterprises moving towards sustainability. Journal of Cleaner Production 192:207-220

139. Li Z, Guo H, Barenji AV, Wang WM, Guan Y, Huang GQ (2020) A sustainable production capability evaluation mechanism based on blockchain, LSTM, analytic hierarchy process for supply chain network. International Journal of Production Research

140. Moro A, Holzer A (2020) A framework to predict consumption sustainability levels of individuals. Sustainability 12(4):1423

141. Francesconi W, Perez Minana E, Willcock S, Villa F, Quintero $M$ (2015) Linking ecosystem services to food security in a changing planet: Assessing Peruvian Amazon deforestation using the artificial intelligence for ecosystem services (ARIES) framework. In: ASABE 1st Climate Change Symposium: Adaptation and Mitigation, pp 325-327

142. Sahoo S, Russo TA, Elliott J, Foster I (2017) Machine learning algorithms for modeling groundwater level changes in agricultural regions of the U.S. Water Resour Res 53(5):38783895

143. Huntingford C, Jeffers ES, Bonsall MB, Christensen HM, Lees $\mathrm{T}$, Yang H (2019) Machine learning and artificial intelligence to aid climate change research and preparedness. Environ Res Lett 14(12): 124007

144. Racah E, Beckham C, Maharaj T, Kahou SE, Prabhat, Pal CJ (2017) Extremeweather: A large-scale climate dataset for semisupervised detection, localization, and understanding of extreme weather events. In: NIPS (Neural information processing systems conference)

145. Jin L, Yao C, Huang X-Y (2008) A nonlinear artificial intelligence ensemble prediction model for typhoon intensity. Mon Weather Rev 136:4541-4554

146. McGovern A, Elmore KL, Gagne DJ, Haupt SE, Karstens CD, Lagerquist R, Smith T, Williams JK (March 2017) Using artificial intelligence to improve real-time decision-making for high-impact weather. Bull Am Meteorol Soc 98(10):2073-2090

147. Mokhtarzad M, Eskandari F, Jamshidi Vanjani N, Arabasadi A (2017) Drought forecasting by ANN, ANFIS, and SVM and comparison of the models. Environmental Earth Sciences 76(21):729

148. Topouzelis K, Papakonstantinou A, Garaba SP (2019) Detection of floating plastics from satellite and unmanned aerial systems (plastic litter project 2018). International Journal of Applied Earth Observation and Geoinformation 79:175-183

149. Exbrayat J-F, Williams M (2015) Quantifying the net contribution of the historical Amazonian deforestation to climate change. Geophys Res Lett 42(8):2968-2976

150. Makkeasorn A, Chang NB, Zhou X (2008) Short-term streamflow forecasting with global climate change implications - A comparative study between genetic programming and neural network models. J Hydrol 352(3-4):336-354

151. Marghany M (2014) Utilization of a genetic algorithm for the automatic detection of oil spill from radarsat-2 sar satellite data. Mar Pollut Bull 89(1-2):20-29

152. Salame CW, Queiroz JCB, de Miranda Rocha G, Amin MM (2012) Mapping the risk of burning in the brazilian amazon with the use of logistic regression and fuzzy inference. Math Geosci 44(3):241-256 
153. Avio CG, Gorbi S, Regoli F (2017) Plastics and microplastics in the oceans: from emerging pollutants to emerged threat. Mar Environ Res 128:2-11

154. González-Rivero M, Beijbom O, Rodriguez-Ramirez A, Bryant DEP, Ganase A, Gonzalez-Marrero Y, Herrera-Reveles A, Kennedy EV, Kim CJS, Lopez-Marcano S, Markey K, Neal BP, Osborne K, Reyes-Nivia C, Sampayo EM, Stolberg K, Taylor A, Vercelloni J, Wyatt M, Hoegh-Guldberg O (2020) Monitoring of coral reefs using artificial intelligence: A feasible and cost-effective approach. Remote Sens 12(3):489

155. Kako S, Morita S, Taneda T (2020) Estimation of plastic marine debris volumes on beaches using unmanned aerial vehicles and image processing based on deep learning. Mar Pollut Bull $155: 111127$

156. Ampatzidis Y, Partel V, Costa L (2020) Agroview: Cloud-based application to process, analyze and visualize UAV-collected data for precision agriculture applications utilizing artificial intelligence. Comput Electron Agric 174:105457

157. Anaya-Romero M, Abd-Elmabod SK, Muñoz-Rojas M, Castellano G, Ceacero CJ, Alvarez S, Méndez M, De la Rosa D (2015) Evaluating soil threats under climate change scenarios in the andalusia region, Southern Spain. Land Degrad Dev 26(5):441449

158. Nunez-Mir GC, Iannone BV, Curtis K, Fei S (2015) Evaluating the evolution of forest restoration research in a changing world: A "big literature" review. New Forest 46(5-6):669682

159. Rodríguez-Soto C, Velazquez A, Monroy-Vilchis O, Lemes P, Loyola R (July 2017) Joint ecological, geographical and cultural approach to identify territories of opportunity for large vertebrates conservation in Mexico. Biodivers Conserv 26(8): 1899-1918

160. Ebrahimi MA, Khoshtaghaza MH, Minaei S, Jamshidi B (2017) Vision-based pest detection based on SVM classification method

161. Schwartz R, Dodge J, Smith NA, Etzioni O (November 2020) Green AI. Commun ACM 63(12):54-63

162. Strubell E, Ganesh A, McCallum A (July 2019) Energy and policy considerations for deep learning in NLP. In: Proceedings of the 57th annual meeting of the association for computational linguistics. Association for Computational Linguistics, pp 36453650. Florence, Italy

163. Lannelongue L, Grealey J, Inouye M (2020) Green algorithms: Quantifying the carbon footprint of computation. ArXiv:2007.07610

164. Spelda P, Stritecky V (2020) The future of human-artificial intelligence nexus and its environmental costs. Futures 117:102531

Publisher's note Springer Nature remains neutral with regard to jurisdictional claims in published maps and institutional affiliations.

\section{Affiliations}

Iván Palomares ${ }^{1,2}$ - Eugenio Martínez-Cámara ${ }^{1} \cdot$ Rosana Montes $^{1}$ (D) - Pablo García-Moral ${ }^{3} \cdot$ Manuel Chiachio $^{1}$. Juan Chiachio $^{1}$ - Sergio Alonso ${ }^{1}$ - Francisco J. Melero ${ }^{1}$ - Daniel Molina ${ }^{1}$ - Bárbara Fernández ${ }^{4}$. ${\text { Cristina } \text { Moral }^{4} \text { - Rosario Marchena }}^{4}$ - Javier Pérez de Vargas ${ }^{5}$ - Francisco Herrera ${ }^{1,5}$

1 Andalusian Research Institute in Data Science and Computational Intelligence (DaSCI), University of Granada, 18071 Granada, Spain

2 Department of Computer Science and Information Engineering, National Cheng Kung University, 70101 Tainan, Taiwan

3 Faculty of Arts, University of Granada, 18071 Granada, Spain

4 Ferrovial S.A., C/ Principe de Vergara 135, 28002 Madrid, Spain

5 Royal Academy of Engineering of Spain, 28005 Madrid, Spain 